\title{
Essays in Applied Economics
}

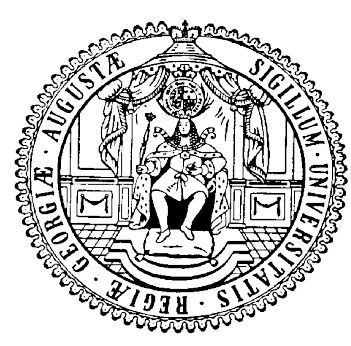

Dissertation

to attain the Ph.D. degree

in the International Ph.D. Program for Agricultural Sciences in

Göttingen (IPAG)

at the

Faculty of Agricultural Sciences,

Georg-August-University Göttingen, Germany

\author{
presented by \\ Oliver Ken Haase \\ born in Kobe, Japan
}

Göttingen, March 2020 
1st Supervisor: Prof. Dr. Bernhard Brümmer

2nd Supervisor: Prof. Xiaohua Yu, PhD

3rd Supervisor: Prof. Dr. Stephan von Cramon-Taubadel

Date of dissertation: March 26, 2020 


\section{Declaration of Authorship}

I, Oliver Ken Haase, declare that this thesis titled, "Essays in Applied Economics" and the work presented in it are my own. I confirm that:

- This work was done wholly while in candidature for a research degree at this University.

- Where any part of this thesis has previously been submitted for a degree or any other qualification at this University or any other institution, this has been clearly stated.

- Where I have consulted the published work of others, this is always clearly attributed.

- Where I have quoted from the work of others, the source is always given. With the exception of such quotations, this thesis is entirely my own work.

- I have acknowledged all main sources of help.

- Where the thesis is based on work done by myself jointly with others, I have made clear exactly what was done by others and what I have contributed myself.

Signed:

Date: 



\section{Abstract}

The first essay of the thesis analyzes the productive efficiency of dairy farms located across the rural-urban transition area of the Southern Indian city of Bangalore. For that purpose a stochastic frontier analysis is conducted on a primary data set comprising 418 dairy farms. This essay employs an instrument-free approach to cope with unobserved characteristics that are correlated with the observable inputs. The results reveal an overuse of high protein content feed which may have critical implications for animal welfare and sustained milk production.

The second essay extends the literature on the productivity effects of labor market institutions by means of a semiparametric production function approach to 191 European regions (NUTS-2) over the period from 1995 to 2008. Rather than focusing exclusively on one particular institution progress is made by examining the effects of a whole set of labor market characteristics. The results indicate that stronger presence of unions, higher firing costs and more generous unemployment benefit payments tend to have detrimental marginal productivity effects, while hetergeneous findings on the effect from higher union coverage depend on the degree of centralization of wage bargaining processes.

The third essay applies the new translog gravity model by Novy (2013) to investigate the heterogeneous effects of food standards on agricultural trade flows. In contrast to existing works, this essay argues that standards affect trade but even more so for countries that trade smaller volumes. The reasoning is simple but hopefully intuitive; bigger trading partners find it more profitable to invest in meeting the costs of importer-specific standards. Consistent with the predictions of the model, the results from the conventional CES model support our argument. However, the crucial difference lies in the capability of the translog model to endogenously explain the standards effect on trade. 



\section{Acknowledgements}

I would like to express my sincere gratitude to my thesis advisor Professor Bernhard Brümmer for sharing his knowledge at any time and for entrusting me with the completion of my dissertation.

I would like to express my sincere appreciation and gratitude to an "old" classmate, friend and colleague, Hannes Greve, from the German Institute of Global and Area Studies (GIGA) for giving unselfishly of his time, his excellent feedback as well as encouragement over the course of my degree.

Sincerest appreciation and thanks to Dela-Dem Doe Fiankor for his support and inspiration for the work done in this dissertation.

I also wish to thank Rouven Schmidt from the Department of Statistics for helping me to further develop and enhance my understanding of statistics.

My deepest gratitude goes to my parents and my brother for their unfading support, love and encouragement along the way. 



\section{Contents}

Declaration of Authorship

Abstract v v

Acknowledgements vii

1 General Introduction 1

2 Revisiting Dairy Farm Efficiency in India:

The Case of Bangalore $\quad 5$

2.1 Introduction . . . . . . . . . . . . . . . 1

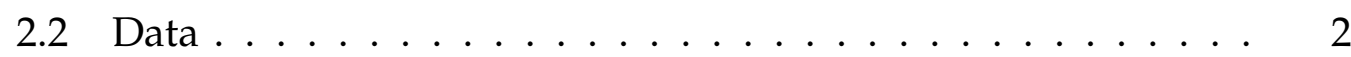

2.3 Methodology .................. 3

2.3.1 Copula Functions . . . . . . . . . . . . 5

2.3.2 Maximum-Likelihood Estimation ........ 7

2.4 Empirical results . . . . . . . . . . . . . . 8

2.5 Conclusion . . . . . . . . . . . . . . . . 12

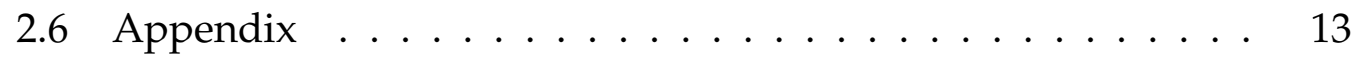

3 Do Labor Market Institutions affect Productivity?

Evidence from Regionally Aggregated Data 24

3.1 Introduction . . . . . . . . . . . . . . . 1

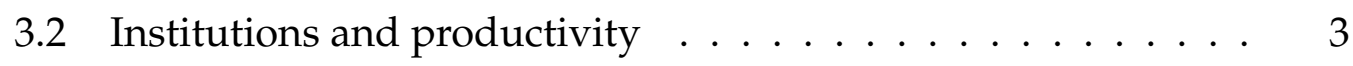

3.3 Data and estimation strategy ............. . . 4

3.3.1 Country and region specific characteristics of European labor markets ................ . . 4

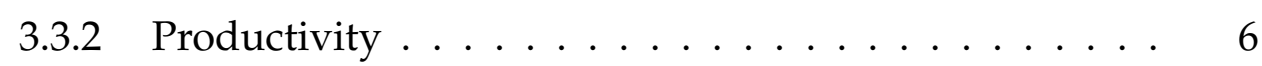

3.3.3 Labor market institutions . . . . . . . . . . . 8

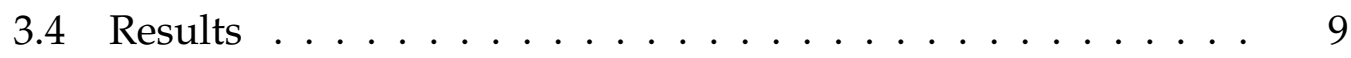

3.5 Concluding remarks $\ldots \ldots \ldots \ldots 11 \ldots \ldots \ldots$

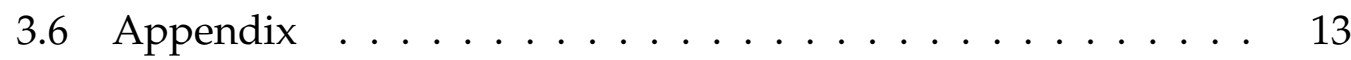


4 The heterogeneous effects of standards $\begin{array}{ll}\text { on agricultural trade flows } & 41\end{array}$

4.1 Introduction . . . . . . . . . . . . . . 1

4.2 Empirical approach . . . . . . . . . . . . . 5

4.3 Data ........................ 8

4.4 Results and discussions . . . . . . . . . . . . 11

4.5 Sensitivity Analysis . . . . . . . . . . . . . . . . . 17

4.5.1 CES gravity model with heterogeneous SPS effects on trade .................... 17

4.5.2 Further robustness checks . . . . . . . . . . 19

4.6 Conclusion . . . . . . . . . . . . . . . . . . 21

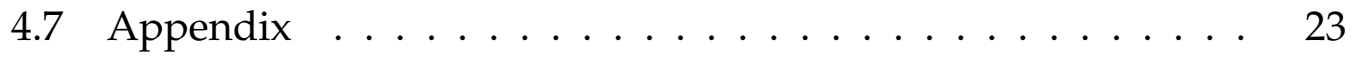

$\begin{array}{ll}\text { Bibliography } & 73\end{array}$ 


\section{List of Figures}

A1.1 Distributions of TE estimates . . . . . . . . . . . .

A1.2 Histogram of estimated residuals and QQ-Plot from the copula SFM. The left figure shows the estimated density as a solid line. The dashed line is the kernel. The right figure shows the QQ-Plot with 95\% simultaneous confidence bands. . . . . . . 14

2.1 Spatial distribution for labor market institutions . . . . . . 6

3.1 Increasing relevance of non-tariff measures $\ldots \ldots \ldots \ldots$

3.2 Trade cost elasticities plotted against import shares . . . . . . 14 



\section{List of Tables}

1.1 Summary statistics $\ldots \ldots \ldots \ldots \ldots \ldots \ldots \ldots$

1.2 Maximum-Likelihood estimates of parameters . . . . . . . 11

A1.1 The estimated correlation matrix $\Sigma \ldots \ldots \ldots \ldots \ldots$

2.1 Output elasticities of the translog production function . . . . 8

2.2 The effect of labor market institutions on regional productivity 10

A2.1 Data Definitions and Sources . . . . . . . . . . . . . 15

3.1 Summary statistics . . . . . . . . . . . . . . . . 11

3.2 The effect of standards on agricultural trade: translog gravity model . . . . . . . . . . . . . . . . . . 12

3.3 Country-pair specific estimates of the effects of EU-15 standards in agricultural trade in $2017 \ldots \ldots$. . . . . . . . 15

3.4 The heterogeneous effect of standards on agricultural trade: standard CES gravity model . . . . . . . . . . . . . . . 18

3.5 Robustness check - translog gravity model: lagged SPS values 20

A3.1 List of importing and exporting countries . . . . . . . . . 27

A3.2 The effect of standards on agricultural trade: standard gravity model using OLS . . . . . . . . . . . . . . . . 28

A3.3 Translog gravity model: Bilateral trade between all exporting and importing countries . . . . . . . . . . . . 28

A3.4 Translog gravity model: count of specific trade concerns _ . . 29

A3.5 The effect of standards on agricultural trade: translog gravity model using PPML . . . . . . . . . . . . . . . . . 30

A3.6 Index of agricultural bilateral trade-cost elasticity between the EU-15 and major trading partners . . . . . . . . . . . 31 



\section{List of Abbreviations}

ACF

AIC

BACI

CEPII

CIF

BFGS

cdf

CES

erf

erfc

EU15

EUROSTAT

FAO

FE

FOB

HACCP

I-TIP

KMF

ML

NTM

NUTS

OECD

OLS

OP

pdf

PPML

RTA

SF

SFA

SFM

SPS

STC
Ackerberg, Caves \& Frazer

Akaike Information Criterion

Base (pour) l'Analyse (du) Commerce International

Centre d'Etudes Prospectives (et) d'Informations Internationales

Cost, Insurance (and) Freight

Broyden Fletcher Goldfarb Shanno

cumulative distribution function

Constant Elasticity (of) Substitution

error function

error function complement

European Union (of) $\mathbf{1 5}$ member states

EUROpean STATistical (Office of the Communities)

Food (and) Agriculture Organization

Fixed Effect (estimator)

Free On Board

Hazard Analysis (and) Critical Control Point

Integrated (-) Trade Intelligence Portal

Karnataka Milk Federation

Maximum (-) Likelihood

Non (-) Tariff Measure

Nomenclature (des) Unités Territoriales Statistiques

Organization (for) Economic Cooperation (and) Development

Ordinary Least Squares

Olley \& Pakes

probability density function

Poisson Pseudo (-) Maximum (-) Likelihood

Regional Trade Agreements

Stochastic Frontier

Stochastic Frontier Analysis

Stochastic Frontier Model

Sanitary (and) Phytosanitary Standards

Specific Trade Concern 


$\begin{array}{ll}\text { TBT } & \text { Technical Barriers (to) Trade } \\ \text { TE } & \text { Technical Efficiency } \\ \text { tfp } & \text { total factor productivity } \\ \text { translog } & \text { transcendental logarithmic } \\ \text { UNCOMTRADE } & \text { United Nations Commodity Trade } \\ \text { UNCTAD } & \text { United Nations Conference (on) Trade (and) Development } \\ \text { WHO } & \text { World Health Organization } \\ \text { WTO } & \text { World Trade Organization }\end{array}$


To those who persevere 



\section{Chapter 1}

\section{General Introduction}

This dissertation consists of three essays. The first essay applies a parametric stochastic frontier (SF) approach with endogenous regressors introduced by Tran and Tsionas (2015) to estimate milk production efficiency of Indian dairy farms. The second essay extends the literature on the productivity effects of labor market institutions by means of a semiparametric approach developed by Olley and Pakes (1996) and Ackerberg et al. (2015) to a set of European (NUTS-2) regions overtime. The third and final essay investigates on heterogeneous effects of food standards on agricultural trade using the structural translog gravity model of Novy (2013) that incorporates predictions from the heterogeneous firms' literature.

In the applied parametric frontier literature it is commonly assumed that inputs are exogenous or, in other words, determined independently from the unit's level of efficiency and other latent determinants unobserved by the econometrician. However, exogeneity would require that information is readily available to explain all variation in measured output in order to correctly specify the production function. Only in this rare circumstance one may believe that Maximum-Likelihood estimation generates unbiased and consistent estimates of all input coefficients. The absence of information on inputs violates the exogeneity condition if this information correlates with the inputs controlled in the production function, or, if variables associated with managerial skill are neglected (Mundlak, 1961). Endogeneity of inputs also arises if inputs in the production function are not independently chosen, but determined by the characteristics of the farm(er) underlying efficiency (Marschak and Andrews, 1944). This refers to the so called simultaneity bias. 
Another customary assumption refers to the mutual independence of between the error components, i.e. noise and efficiency. However, Pal and Sengupta (1999) and Smith (2008) argue that there is neither statistical nor economic rationale to assume orthogonality between noise and inefficiency since weather shocks and seasonal fluctuations most likely affect farming decisions. Error dependence may also arise due to unobserved inputs if simultaneity between inputs and inefficiency is present.

The first essay provides a parametric estimation of milk yield efficiencies of Indian dairy farm households located in and around the Southern Indian city of Bangalore. This essay relaxes the assumption of input exogeneity and considers unobserved characteristics to be correlated with observed use of concentrates without using instrumental variables.

The typical way to cope with endogeneity is to rely on instrumental variables. Valid instruments are required to be uncorrelated with the error term. This requirement needs a strong theoretical backup and can in general not be tested. Also, the composed error setting makes it particularly challenging to rule out any direct effect of the instruments on the dependent variable or any effect running through omitted variables absorbed either by the noise term or by the inefficiency.

This essay employs a copula function to parametrize the joint behaviour of the composed error and the observed inputs which gives the data the possibility to dispose of the exogeneity assumption. The approach used in this essay is motivated by the experience that Indian dairy farmers' capacity to record quantities on forage production and consumption is limited. Econometrically, the presence of latent major input factors such as forage decouples the production process of milk from milk yield registration. Failure to account for all inputs represents misspecification which causes a bias in the remaining parameter estimates of the production function with further critical implications for efficiency scores in the realm of Stochastic Frontier (SF) analysis. Further, major inputs such as forage can be expected to be related to observed levels of concentrate feed since both are typically either complements or substitutes depending on the season. This causes the endogeneity problem.

The results indicate that unobserved milk yields determinants are present and affect technical efficiency levels, but not rankings. Accounting for those latent effects the estimated milk yield elasticities with respect to high-protein concentrate feed and labor become negative. 
The second essay foregoes the usual distributional assumption for inefficiency due to data aggregation. Here, regional production is represented by the sum over all firm production within the region. Enforcing the customary assumption of a half-normal distribution for instance results in meaningless technical efficiency measures as the distribution of a sum of a one-sided independent and identically distributed random variable converges towards a normal distribution according to the central limit theorem. As a result, efficiency disappears into noise and findings on high efficiency levels from regional data are spurious especially if the number of firms per region is high. ${ }^{1}$ A purely nonparametric approach such as the Data Envelopment Analysis (DEA) dispenses with the requirement for an explicit functional form of the production technology but at the cost of the assumption that all deviations from the frontier are entirely attributed to inefficiency. Instead, this essay maintains a parametric specification of the production function but chooses a nonparametric representation of the inefficiency in the context of regionally aggregated data. Output measured in value added is a function of capital, labor and unobserved productivity. A productivity measure is backed out from the residual to evaluate the impact of labor market institutions. The estimation exploits the panel data structure to cope for unobserved heterogeneity but relaxes the traditional fixed effect assumption. The so called control function approach introduced by Olley and Pakes (1996) used in this essay introduces flexibility by making unobserved heterogeneity a time-varying estimable function of observables. This applies some structure to the decisionmaking process of the underlying firms.

The final results from the second stage of the estimation procedure indicate that stronger presence of unions, higher firing costs and more generous unemployment benefit payments tend to have detrimental marginal productivity effects, while the results on positive effects from higher union coverage at lower levels of centralization of wage bargaining processes support efficiency wage views.

The third essay is on trade. This essay revisits the "standards-as-barriersto-trade" debate using Novy's (2013) somewhat more flexible translog specification to investigate the trade effects of public food standards. Public food standards imposed by importing countries may be endogenous to bilateral

\footnotetext{
${ }^{1}$ See Brorsen and Kim (2013) on the discussion on data aggregation in stochastic frontier models.
} 
trade volumes. The panel data used in this essay allows to control for timeinvariant factors such as distance, contiguity and language etc. in the estimation by including country-pair fixed effects. Potentially time-varying omitted variables are parsimoniously controlled by importer- and exporterspecific time-varying effects. Consistent with the predictions derived from the more restrictive CES model, the results from the more flexible translog specification support the argument that stricter standards are indeed traderestrictive. However, the estimated trade cost elasticity varies depending on how intensively two countries trade, which means that for countries trading large volumes, standards have only limited negative effects. 


\title{
Chapter 2
}

\section{Revisiting Dairy Farm Efficiency in India: \\ The Case of Bangalore}

\begin{abstract}
In this paper we analyze the productive efficiency of dairy farms across the rural-urban intersect of the Southern Indian city of Bangalore. We conduct a stochastic frontier analysis on a primary data set comprising of 418 dairy farms spread along the transition area. We employ an instrument-free approach to cope with unobserved milk yield determinants that are possibly correlated with observed usage of concentrates, compound feed and labor. Our results show that an increase in concentrate feed at the mean leads to a considerable decline in milk yields. Conditional on the presence of latent input factors, such as green and dry forage, our finding indicates an overuse of high-protein feeds.
\end{abstract}

This chapter is a joint work with Rouven Schmidt.

Acknowledgements: We acknowledge comments from Alexander Silbersdorff.

Author contributions: Haase O.K collected the data, conceptualised the idea, carried out the analysis and wrote the paper. Schmidt R. provided the statistical model and wrote the paper. 


\subsection{Introduction}

In Bangalore, a large dairy cooperative sector supports its members in the provision of processed fodder such as concentrate feed, compound feed as well as veterinary services, but has been unable to effectively address the problem of deficient and imbalanced feeding (Pratap and Jha, 2005). Yield gaps defined as the difference between feasible and de facto yields are also more pronounced as imported breeds with higher milk yield capacities require higher caloric intakes than native breeds. This adds pressure to agricultural production characterised by small-scale farming and affected by frequent droughts to generate and coordinate sufficient amounts of green and dry forage.

We make a contribution to the relatively sparse economic literature on technical efficiency of Indian dairy production and apply the approach proposed by Tran and Tsionas (2015) which extends the conventional likelihood by the density of a copula function to extract the information on unobserved milk yield determinants. Our application of their approach is motivated by the experience that the Indian dairy farmers' capacity to record quantities on forage production and consumption is fairly limited. ${ }^{1}$ Therefore, the production process of milk is disjoined from milk yield registration due to lacking information on input factors. Forage represents a major input factor which usually cannot be measured without a considerable amount of noise. ${ }^{2}$ Importantly, high-protein feed has to be accompanied at any level by forage in order to become effective in terms of milk yields. Econometrically, failure to account for all inputs represents a misspecification which causes a bias in the remaining parameter estimates of the production function with further critical implications for efficiency scores in the realm of stochastic frontier analysis. That is why we relax the exogeneity assumption of inputs and allow them to be correlated with the noise term containing the information on unobserved inputs. Furthermore, this approach also deals with the possible simultaneity between input choice and (in)efficiency. This is in stark contrast to the existing literature that strictly poses the assumption that all inputs are given, and can be controlled for. ${ }^{3}$

\footnotetext{
${ }^{1}$ This contrasts to Dikshit and Birthal (2010) who argue that household level surveys are the only way to obtain reliable data on actual feed consumption.

${ }^{2}$ Forage in this particular region mainly consists of perennial grass, maize or crop residues sourced on- or off-farm via in kind payments.

${ }^{3}$ To the best of our knowledge the TE literature on Indian dairy farming comprises the work of Sharma et al. (2003), Saha and Jain (2004) and Rajendran and Mohanty (2005).
} 
In the applied agricultural literature, Ahmadzai (2017) uses the instrumental variable approach proposed by Karakaplan (2016) to cope for simultaneity between inefficiency and input choice. Yet, others (e.g. Wiboonpongse et al., 2015; Nunti et al., 2019) opt for a copula approach to display a correlation between the components of the composed error term consisting of inefficiency and the noise. Our work differs from those applications as we employ a model that takes into account the correlation between observed inputs and the composed error term as a whole. This approach is more general since we do not have enough information on the source of the correlation (i.e. valid instruments to cope for simultaneity between inputs and inefficiency and/or dependence between error terms due to unobserved inputs).

We argue that major inputs such as forage are related to observed levels of concentrate feed since both are typically interrelated either as complements or substitutes. Sometimes it may be more profitable for dairy producers to limit forage intake and feed concentrates more intensively. ${ }^{4}$ Drought generally requires producers to limit forage intake because of limited availability.

Our results indicate that unobserved determinants are present and affect milk yields as well as farm-level efficiency levels. The preferred copula approach reveals that latent effects run through the use of observed inputs. In particular, an increase in the use of concentrate feed leads to a decline in milk yields at the margin with possible detrimental effects on animal welfare, and thus future milking performance. However, our results also show that efficiency distribution shifts towards the production frontier because latent milk yield drivers are taken into account.

This paper is organized as follows. Section 2 briefly describes the data set to be analyzed. Section 3 discusses the methodology. Results are then presented in section 4 . And, section 5 concludes.

\subsection{Data}

This present study relies on the information obtained from the sample of 418 dairy farm households collected in 2016/17 from the Southern Indian region of Bangalore to estimate a common production frontier. Homogeneity of production technologies is imposed since all farm units in the sample are members of the Karnataka Milk Federation (KMF). Cooperative membership ensures access to concentrate feed, compound feed, assistance for

\footnotetext{
${ }^{4}$ Forage is defined as plant materials for consumption by an animal and roughage refers to a feedstuff with a higher fiber content. The terms are used interchangeably.
} 
animal breeding and veterinary services offered at subsidized rates. Milk is gathered at collection centers run by the KMF in each of the 55 villages covered in this sample. Our primary data include information on output defined as the total milk production per year in litres sold at collection centers and corrected for household consumption. Labor is measured in full-man days including family and hired labor. Differences in total milk production per household are explained by the annual number of milching cows and variable input quantities controlled by farmers, namely labor and the amount of fodder. We used fodder composition tables to quantify each purchased item. These are categorized as concentrate feed and compound feed measured in kilogram. Reliable information on forage production and consumption are unavailable, and thus taken into account by the econometric modelling approach. Herd compositions are considered as percentage shares of crossbred cows, indigenous cows and buffaloes among herds. Crossbred cattle for instance are genetically closer to the high-performing Holstein-Friesian cattle, and determine the milk yield capacity of the household. Breed shares are therefore considered as shifters of the production frontier. We also include land, measured in acres of land used for the cultivation of fodder as a proxy for forage production.

TABLE 1.1: Summary statistics

\begin{tabular}{lcrrr}
\hline Variable & Mean & Std. Dev. & Min. & Max. \\
\hline Milk yield (in ltr per per hh) & 4140.89 & 766.865 & 51 & 4406 \\
Herdsize (per hh) & 3.25 & 1.216 & 1 & 8 \\
Share of Crossbred (in percent per hh) & 91 & 0.252 & 0 & 100 \\
Share of Indigenous (in percent per hh) & 8 & 0.247 & 0 & 100 \\
Share of Buffaloes (in percent per hh) & 1 & 0.058 & 0 & 100 \\
Concentrates (in kg per hh) & 633.75 & 331.357 & 0 & 1934 \\
Compound feed (in kg per hh) & 1683 & 1198.043 & 1 & 10502 \\
Labor (in full man-days per hh) & 248.93 & 102.552 & 45.63 & 775.63 \\
Land (in acres per hh) & 2.34 & 2.303 & 0 & 9.83 \\
\hline
\end{tabular}

\subsection{Methodology}

Closing yield gaps at the farm level represents an important task and an early prerequisite of structural change. We therefore assess the status quo of production potentials by using the parametric frontier approach (Aigner et al., 
1977; Meeusen and van Den Broeck, 1977). In the developing country setting where the probability of data being influenced by measurement errors is relatively high, a parametric frontier approach with a composed error term is more appropriate (Coelli et al., 1998). Parametric approaches to the measurement of TE require the choice of a specific functional form for the production technology. We assume a homogeneous Cobb-Douglas type production function written in the following form for the purpose of empirical estimation: ${ }^{5}$

$$
y_{i}=\alpha_{0}+\gamma_{i j}+\sum_{d=1}^{D=2} \alpha_{d} z_{i d}+\sum_{p=1}^{P=3} \beta_{p} x_{i p}+v_{i}-u_{i}
$$

where $y_{i}$ denotes the milk yield of the $i$-th farm; the endogenous inputs $x_{i p}$, with $p=1,2,3$, comprise concentrate feed, compound feed and labour. The exogeneous inputs $z_{i d}$, with $d=1,2$, represent land and herdsize held by farm $i$. We consider levels of concentrate feed and compound feed as endogenous inputs since these have to be accompanied by unobserved quantities of forage in order to become effective in terms of yields. Thus, we would expect a strong correlation with the composed error term. We also assume labor to be endogenous since effort is required to collect forages. The common intercept $\alpha_{0}$ represents mean efficiency. To control for some unobserved heterogeneity related to geography and neighborhood ties we include a dummy, $\gamma_{i j}$, for each village, $j=1, \ldots, J=55$, in our regression. The parameters $\alpha_{d}$ and $\beta_{p}$ are the respective output elasticities to be estimated. Farm specific milk yields are further determined by a symmetric random error, $v_{i} \sim N\left(0, \sigma_{v}^{2}\right)$, with constant variance and a one-sided random term, $u_{i} \sim N_{+}\left(0, \sigma_{u}^{2}\right)$, associated with technical inefficiency. The composed error term is defined as $\epsilon_{i}=v_{i}-u_{i}$.

We utilize the information on observed inputs to account for output variation that stems from latent inputs according to:

$$
x_{i p}=\delta w_{i p}+\eta_{i p}
$$

We impose the exclusion restriction for latent inputs, $w_{i p}$, which are assumed to linearly affect $x_{i p}$. Endogeneity thus arises through $\operatorname{cov}\left(\epsilon_{i}, \eta_{i p}\right) \neq 0$.

\footnotetext{
${ }^{5}$ We forego the flexible translog specification since the inclusion of square and interacted terms of endogenous variables most likely introduces additional biases into the model.
} 
Pal and Sengupta (1999) and Smith (2008) argue that there is neither statistical nor economic rationale to assume orthogonality between noise and inefficiency since weather shocks and seasonal fluctuations most likely affect farming decisions. We argue for our cross-sectional data, that weather conditions merely reflect a state that commonly affects all farm units. Dependence may instead arise in this case from unobserved inputs chosen by the farmers which is taken into account by the estimation procedure. Hence, we denote the marginal probability density function (pdf) of $\epsilon$ as introduced by Weinstein (1964) as:

$$
f_{\epsilon}\left(\epsilon_{i}\right)=\frac{2}{\sigma} \phi\left(\frac{\epsilon_{i}}{\sigma}\right) \Phi\left(-\frac{\lambda \epsilon_{i}}{\sigma}\right)
$$

with $\sigma=\sqrt{\sigma_{v}^{2}+\sigma_{u}^{2}}$ and $\lambda=\frac{\sigma_{u}}{\sigma_{v}}$. The functions $\phi(\cdot)$ and $\Phi(\cdot)$ denote the probability density function and cumulative distribution function (cdf) of a standard normal random variable, respectively.

The dependency of $x_{i p}$ and $\epsilon_{i}$ is explicitly accounted for by the joint pdf of $x_{i p}$ and $\epsilon_{i}, f\left(x_{i 1}, x_{i 2}, x_{i 3}, \epsilon_{i}\right)$ using a copula function. The concept of a copula will be briefly introduced in the next section.

\subsubsection{Copula Functions}

The copula function used in the Tran and Tsionas (2015) specification is a $(P+1)$-dimensional distribution function with standard uniform margins:

$$
C\left(F_{1}\left(x_{i 1}\right), \ldots, F_{P}\left(x_{i P}\right), F_{\epsilon}\left(\epsilon_{i}\right)\right):[0,1]^{P+1} \rightarrow[0,1]
$$

Here $F_{p}\left(x_{i p}\right)$ denotes the marginal cumulative distribution function of $x_{i d}$. The cumulative distribution function of $\epsilon$ was introduced by Amsler et al. (2019) and is denoted as:

$$
F_{\epsilon}\left(\epsilon_{i} \leq \kappa\right)=F_{\epsilon}(\kappa)=2 \mathcal{T}\left(\frac{\kappa}{\sigma}, \lambda\right)+\Phi\left(\frac{\kappa}{\sigma}\right)
$$

where $\mathcal{T}(\cdot)$ is the Owen's T function introduced by Owen (1956). ${ }^{6}$

A fundamental result of copula theory is Sklar's theorem which describes the role that copulas play in the relationship between multivariate distribution functions and their univariate margins. Sklar's theorem shows that the univariate margins and the multivariate dependence can be separated in a such a way that the multivariate dependence structure is represented by the

\footnotetext{
${ }^{6}$ In the original model by Tran and Tsionas (2015), $F_{\epsilon}\left(\epsilon_{i}\right)$ is approximated by a numeric integral of $f_{\epsilon}\left(\epsilon_{i}\right)$. In this work, the analytical integral is used. Consequentially, the results are more accurate and the estimation procedure converges faster.
} 
copula independently of the choice of the margins. Thus the joint cumulative distribution function can be written using a copula and the marginal cdfs as:

$$
F_{1, \ldots, P, \epsilon}\left(x_{i 1}, \ldots, x_{i P}, \epsilon_{i}\right)=C\left(F_{1}\left(x_{i 1}\right), \ldots, F_{P}\left(x_{i P}\right), F_{\epsilon}\left(\epsilon_{i}\right)\right)
$$

Differentiation leads to multivariate pdf of the form:

$$
f_{1, \ldots, P, \epsilon}\left(x_{i 1}, \ldots, x_{i P}, \epsilon_{i}\right)=c\left(F_{1}\left(x_{i 1}\right), \ldots, F_{P}\left(x_{i P}\right), F_{\epsilon}\left(\epsilon_{i}\right)\right) f_{\epsilon}\left(\epsilon_{i}\right) \prod_{p=1}^{P} f_{p}\left(x_{i p}\right)
$$

where $c(\cdot)$ denotes the pdf of the copula. Let $\rho$ be a vector of parameters of the copula called the dependence parameter which measures dependence between the marginal cdfs. It is important to note that each of the array of copula functions enforces certain characteristics regarding the modelled dependence. For example, the independence copula enforces exogeneity on all variables. Choosing this copula results in the standard SF model. The Gaussian copula models linear dependence between each of the endogenous variables and the composed error. The density of the Gaussian copula with parameter correlation matrix $\Sigma \in[-1,1]^{(P+1) \times(P+1)}$ to be estimated is defined as:

$$
\begin{aligned}
c(\cdot)=|\Sigma|^{-\frac{1}{2}} \exp \left\{-\frac{1}{2}[\right. & \left.\Phi^{-1}\left(F_{1}\left(x_{i 1}\right)\right), \ldots, \Phi^{-1}\left(F_{\epsilon}\left(\epsilon_{i}\right)\right)\right]^{\prime} \\
& \left.\left(\Sigma^{-1}-I_{P+1}\right)\left[\Phi^{-1}\left(F_{1}\left(x_{i 1}\right)\right), \ldots, \Phi^{-1}\left(F_{\epsilon}\left(\epsilon_{i}\right)\right)\right]\right\}
\end{aligned}
$$

where $\Phi^{-1}(\cdot)$ is the quantile function of the normal distribution and $I_{P+1}$ denotes the identity matrix with dimension $P+1$. To model the joint pdf, the marginal pdfs are required. The marginal distribution of the data $x_{i p}$ is assumed to be the empirical distribution function (ecdf) defined as:

$$
\tilde{F}_{n p}(t)=\frac{1}{n+1} \sum_{i=1}^{n} \mathbf{1}_{X_{i p} \leq t}
$$

The rescaling factor $1 /(n+1)$ of the ecdf is chosen over $1 / n$, so that $\tilde{F}_{n p}(t)<$ 1. Thus the domain of $X_{i p}$ is not bounded. ${ }^{7}$ The asymptotic distribution of the ecdf with $1 /(n+1)$ and $1 / n$ is the same, as both factors converge to 0 . With this information the joint $\operatorname{cdf} F_{1, \ldots, P, \epsilon}\left(x_{i 1}, \ldots, x_{i 3}, \epsilon_{i}\right)$ and pdf $f_{1, \ldots, P, \epsilon}\left(x_{i 1}, \ldots, x_{i 3}, \epsilon_{i}\right)$

\footnotetext{
${ }^{7}$ The denominator takes the value $n+1$ to circumvent the fallacy that the minimum and maximum value for one variable in our sample are representative for the population as a whole.
} 
is specified. Consequently, the parameters can be estimated by MaximumLikelihood (ML).

\subsubsection{Maximum-Likelihood Estimation}

The parameters of the model are estimated via Maximum-Likelihood (ML) estimation. Let $\boldsymbol{\theta}=\left(\beta_{1}, \ldots, \beta_{P}, \alpha_{1}, \ldots, \alpha_{D}, \lambda, \sigma, \Sigma, \gamma_{1}, \ldots \gamma_{J}\right)$ be the vector of parameters for the joint density. The ML estimator of $\boldsymbol{\theta}$ is defined as:

$$
\hat{\boldsymbol{\theta}}=\underset{\boldsymbol{\theta} \in \boldsymbol{\Theta}}{\operatorname{argmax}} L(\boldsymbol{\theta})
$$

where $\boldsymbol{\Theta}$ denotes the parameter space of $\boldsymbol{\theta}$. Under the Fisher regularity conditions, the MLE can be shown to be consistent, asymptotically efficient and asymptotically normal, that is,

$$
\sqrt{n}\left(\hat{\boldsymbol{\theta}}-\boldsymbol{\theta}_{0}\right) \rightarrow^{a} N\left(\mathbf{0}, F I\left(\boldsymbol{\theta}_{0}\right)^{-1}\right)
$$

where $\boldsymbol{\theta}_{0}$ is the vector of true parameters and $\left.F I\left(\boldsymbol{\theta}_{0}\right)\right)$ is the Fisher information matrix.

The Likelihood function of the model is given by:

$$
\begin{aligned}
L(\boldsymbol{\theta}) & =\prod_{n=1}^{n} f_{1, \ldots, P, \epsilon}\left(x_{i 1}, \ldots, x_{i 3}, \epsilon_{i}\right) \\
& =\prod_{n=1}^{n} c\left(F_{1}\left(x_{i 1}\right), \ldots, F_{P}\left(x_{i P}\right), F_{\epsilon}\left(\epsilon_{i}\right)\right) f_{\epsilon}\left(\epsilon_{i}\right) \prod_{p=1}^{P} f_{p}\left(x_{i p}\right),
\end{aligned}
$$

The first term of the Likelihood function reflects the dependence structure between endogenous variables and the composed error captured by a Gaussian copula $c(\cdot)$. If there is no endogeneity, the joint pdf is the product of the marginal pdfs and thus the likelihood collapses to the normal-half-normal likelihood function under exogeneity.

Taking logs yields the Log-Likelihood function to be maximized:

$$
\log L(\boldsymbol{\theta})=\sum_{n=1}^{n} \log \left(c\left(F_{1}\left(x_{i 1}\right), \ldots, F_{P}\left(x_{i P}\right), F_{\epsilon}\left(\epsilon_{i}\right)\right)\right)+\log \left(f_{\epsilon}\left(\epsilon_{i}\right)\right)+\sum_{p=1}^{P} \log \left(f_{p}\left(x_{i p}\right)\right)
$$


The marginal density $f_{p}\left(x_{i p}\right)$ is not a function of the set of parameters $\boldsymbol{\theta}$, and thus reflects an additive constant. As a consequence the log-likelihood to be maximised can be written as:

$$
\log L(\boldsymbol{\theta})=\sum_{n=1}^{n} \log \left(c\left(F_{1}\left(x_{i 1}\right), \ldots, F_{P}\left(x_{i P}\right), F_{\epsilon}\left(\epsilon_{i}\right)\right)\right)+\log \left(f_{\epsilon}\left(\epsilon_{i}\right)\right)
$$

The optimization is done by using the BFGS routine. The analytical gradients of the log-likelihood are implemented to increase accuracy and speed, and are provided in the Appendix. The algorithm converges after 20 iterations.

Using the Log-Likelihood obtained from the estimation procedure, we can compute information criteria like the Akaike Information Criterion (AIC). These can be utilized to assess the quality of statistical models. We use the AIC defined as $A I C=-2 * \log L(\boldsymbol{\theta})+2 * \operatorname{dim}(\boldsymbol{\theta})$, to choose between the standard SFM and the Gaussian copula SFM. The specification with the lower AIC value qualifies to be the better performing model.

\subsection{Empirical results}

Table 2 reports ML estimates of the standard SFM under exogeneity in column (1) and estimates for the Gaussian copula SFM assuming endogeneity for concentrate feed, compound feed and labor in column (2). Identification requires the presence of at least one inefficient dairy farm (i.e. $\sigma_{u} \neq 0$ ) irrespective of the distributions of endogeneous regressors. If $\sigma_{u}=0$, the distribution of the composed error follows a normal distribution and model identification with only one symmetric error term would critically hinge on the non-normality of endogenous variables (Park and Gupta, 2012). In other words, due to the stable property of the normal distribution one could not assign the variation to the error term or the distribution of the endogenous variables. To exclude the identification issue we test the hypothesis: $H_{0}: \sigma_{u}=0$, using the Kodde \& Palm test. The significant parameter estimates for $\sigma_{u}$ at the $1 \%$ level signal the existence of inefficiency for both specifications. The relatively high estimate for $\sigma_{u}(0.860)$ also indicates that the model is correctly identified (Tran and Tsionas, 2015). However, we soundly reject the standard SFM in favour of the Gaussian copula SFM on the basis of the AIC. Accordingly, the standard SFM under exogeneity would be most likely misspecified. As a result imposing exogeneity under omitted inputs leads to overall lower 
levels of efficiency. ${ }^{8}$ The Spearman's rho of 0.7 underlines a rather strong relation in terms of ranks. The null of no dependency between the efficiency estimates can be rejected at the one percent probability of error.

With regard to the parameter estimates of the production frontier, note that scale elasticities cannot be identified if input factors are missing.

Monotonicity condition of the Cobb-Douglas specification requires the partial production elasticities of the inputs to be non-negative; this holds true for all estimates in the standard SFM under exogeneity which are mostly signifcant at the one percent level except for land and compound feed which are insignificant. Herd size unsurprisingly shows the highest point estimates in both specifications. Also, the elasticity estimate for an increase in herd size conditional on breeds indicates that a higher share of crossbred animals relative to indigenous tends to increase the milk yield capacity and vice versa.

The coefficient for land is found to be significant in the Gaussian copula SFM. The insignificant estimate for land in the standard SFM might be explained by underlying confounding factors. ${ }^{9}$ We would therefore assume that the estimate obtained from the Gaussian copula SFM is "adjusted" for all confounding factors. Even though land represents a fixed input factor the amount land devoted to the production of fodder may still vary conditional on farmers' choice.

Again, as for land, omitted variables might confound the estimate for compound feed. Weighting the likelihood by the copula function would take into account omitted nutrient sources such as green fodder, silage etc. required for the animal to effectively digest compound and high-protein feed. Interestingly, conditional on those latent inputs higher use of high-protein concentrates significantly decreases milk yields. A ten percentage increase in annual use of concentrates at the mean is associated with almost a five percent decline in milk yields, whilst the standard SFM indicates a positive impact. The sign reversal and the magnitude of the coefficient for concentrate may indicate that relationships with unobserved milk yield drivers are more pronounced than with compound feed. The negative sign on concentrate feed may also reflect a seasonal effect since the survey was undertaken throughout the dry season (i.e. from November 2016 to April 2017). During this period farmers may opt for a higher use of concentrates due to limited

\footnotetext{
${ }^{8}$ The distributions of technical efficiency estimates from both models are provided in the Appendix A1.1.

${ }^{9}$ Land quality may reflect a confounding factor which contaminates the estimate for land in the standard SFM. However, we assume that the small size of the study area would limit the variation of land quality.
} 
forage availability. However, excess protein bears the risk of high levels of ammonia which can cause a toxic uterine environment leading to a reduction in fertility and sustained low yields (e.g., Jordan et al., 1983; Laven and Drew, 1999).

Similarly, the Gaussian copula SFM exposes a significant and negative effect from higher labor, whilst the standard SFM indicates the reverse. A possible explanation for the negative sign might be that labor exists in surplus because most dairy farmers rely entirely on family labor. 
TABLE 1.2: Maximum-Likelihood estimates of parameters

\begin{tabular}{|c|c|c|}
\hline \multirow{3}{*}{ Dependent variable } & SF & Copula \\
\hline & $\mathrm{y}$ & $\mathrm{y}$ \\
\hline & $(1)$ & (2) \\
\hline \multirow[t]{2}{*}{ Intercept } & -1.266 & $-1.202^{* * *}$ \\
\hline & $(0.680)$ & $(0.039)$ \\
\hline \multirow[t]{2}{*}{ Herd size } & $0.636^{* * *}$ & $0.628^{* * *}$ \\
\hline & $(0.092)$ & $(0.012)$ \\
\hline \multirow[t]{2}{*}{ Share of Crossbred } & $0.313^{* * *}$ & $0.293^{* * *}$ \\
\hline & $(0.100)$ & $(0.016)$ \\
\hline \multirow[t]{2}{*}{ Land } & 0.031 & $0.013^{* *}$ \\
\hline & $(0.045)$ & $(0.006)$ \\
\hline \multirow[t]{2}{*}{ Compound feed } & 0.043 & $0.049^{* *}$ \\
\hline & $(0.044)$ & $(0.021)$ \\
\hline \multirow[t]{2}{*}{ Concentrates } & $0.336^{* * *}$ & $-0.468^{* * *}$ \\
\hline & $(0.057)$ & $(0.138)$ \\
\hline \multirow[t]{2}{*}{ Labor } & $0.345^{* * *}$ & $-0.042^{* *}$ \\
\hline & $(0.047)$ & $(0.017)$ \\
\hline \multirow[t]{2}{*}{$\sigma_{u}$} & $0.499^{* * *}$ & $0.860^{* * *}$ \\
\hline & $(0.103)$ & $(0.133)$ \\
\hline \multirow[t]{2}{*}{$\sigma_{v}$} & $0.373^{* * *}$ & $0.439^{* * *}$ \\
\hline & $(0.047)$ & $(0.068)$ \\
\hline Mean TE & 0.398 & 0.670 \\
\hline AIC & 689.242 & 551.630 \\
\hline Observations & 418 & 418 \\
\hline
\end{tabular}

Notes: Standard errors in parentheses, which were computed utilizing the estimated Hessian. $* * * * *, *$ denote significance at $1 \%, 5 \%$ and $10 \%$ respectively. The significance level was determined using the Likelihood-ratio test for all parameters except $\sigma_{u}$. The Kodde \& Palm test was used, to determine the significance of $\sigma_{u}$. The dependent variables in Columns (1) and (2) were logged annual milk yields in liters. Village dummies were included in both specifications and are not reported. 


\subsection{Conclusion}

In this paper we estimate a stochastic frontier with endogenous regressors without using instrumental variables as suggested by Tran and Tsionas (2015) to examine dairy farm efficiency in the Southern Indian region of Bangalore. Dairy production in Bangalore provides an empirical motivation for the considered econometric set-up for which we find some indication for the presence of unobserved milk yield determinants. In particular, we utilize a copula function approach to drag out the information on output variation that is either due to missing inputs or variables referring to managerial skills but are correlated with levels of concentrate and compound feed use as well as labor. Concentrates pose a natural candidate for endogeneity as its impact on milk yields critically depends on the consumption of forage which is unobserved by the econometrician. Hence, they are omitted variables in the production function and the structural error is supposed to capture consumption differences in forages. Unobserved farm-specific factors correlated with inputs lead to efficiency levels that are on average higher than those obtained from the exogenous frontier model. A comparison of parameter estimates of the endogenous variables shows a substantial bias for those obtained from conventional SFA under exogeneity. If unobserved milk yield drivers are prevalent, the exogenous effect from higher concentrate provision on milk is negative. This result may partially reflect a seasonal effect as the survey for the primary data used in this study took place throughout the dry season. Farmers may opt for a relatively higher use of concentrates during this period due to limited forage availability. However, excess protein can cause rebreeding problems leading to sustained low farm yields. We also find a negative effect of higher labor input when latent effects are taken into account. Meanwhile, in the absence of opportunities to attain reasonable estimates on forage production and consumption the copula based approach may compensate for the lack of the information. Verification of estimates from this method can be partially expected if geo-referencing techniques can be combined with the information from on-site plant samples to arrive at meaningful proxies for the quantity of produced forage. 


\subsection{Appendix}

FIGURE A1.1: Distributions of TE estimates
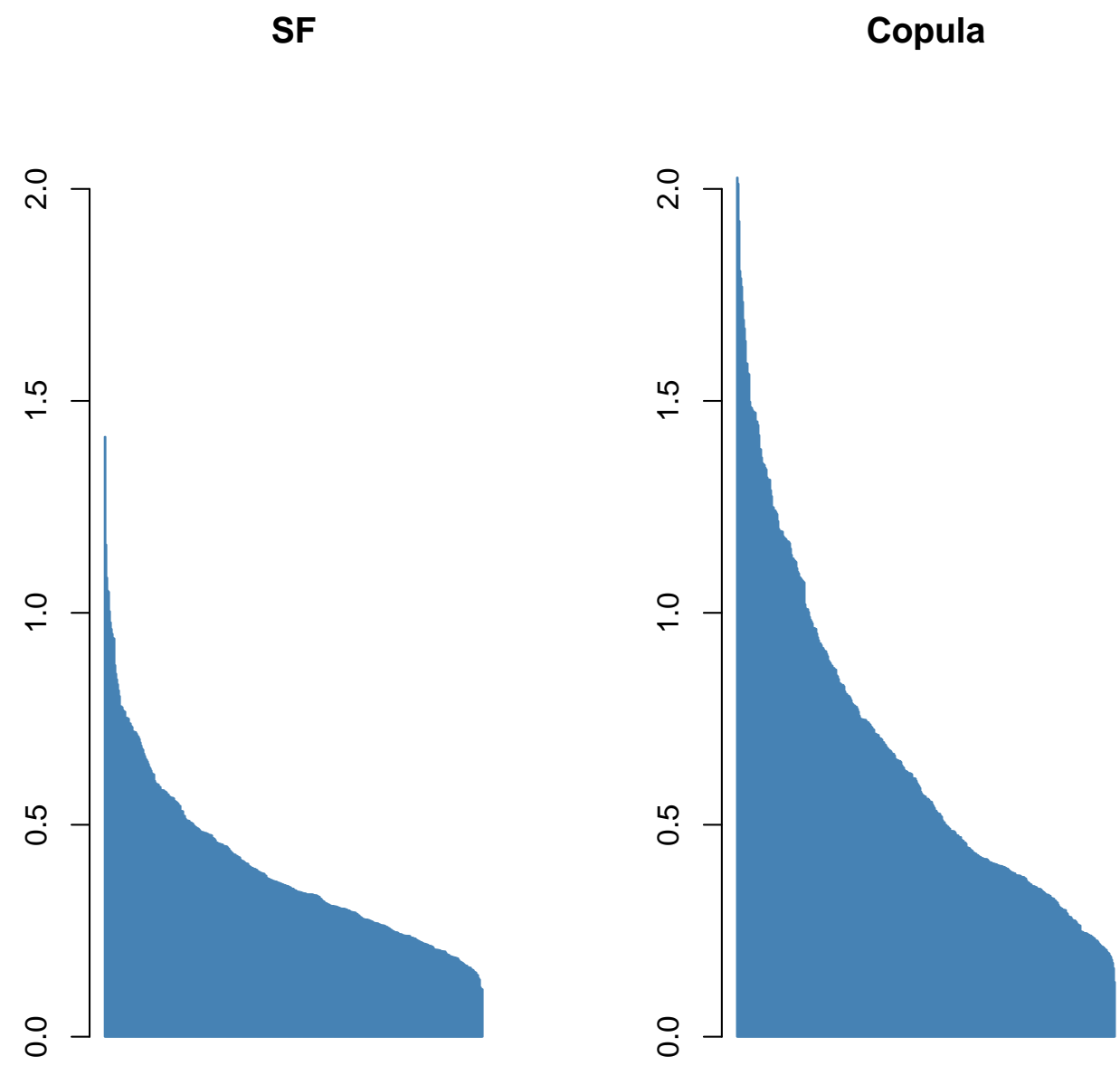

TABLE A1.1: The estimated correlation matrix $\Sigma$

\begin{tabular}{c|cccc} 
& Compound Feed & Concentrate Feed & Labor & Composed Error \\
\hline Compound Feed & 1.000 & 0.511 & 0.123 & 0.347 \\
Concentrate Feed & 0.511 & 1.000 & 0.193 & 0.707 \\
Labor & 0.123 & 0.193 & 1.000 & 0.202 \\
Composed Error & 0.347 & 0.707 & 0.202 & 1.000
\end{tabular}


FIGURE A1.2: Histogram of estimated residuals and QQ-Plot from the copula SFM. The left figure shows the estimated density as a solid line. The dashed line is the kernel. The right figure shows the QQ-Plot with 95\% simultaneous confidence bands.

Histogram of Estimated Residuals

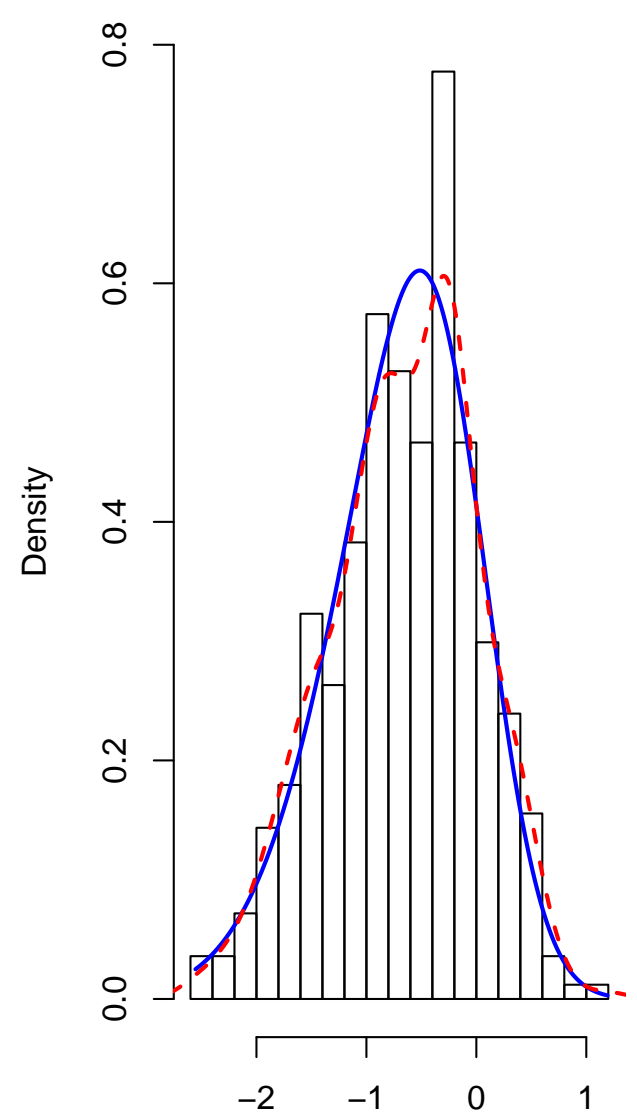

Estimated Residuals
QQ-Plot

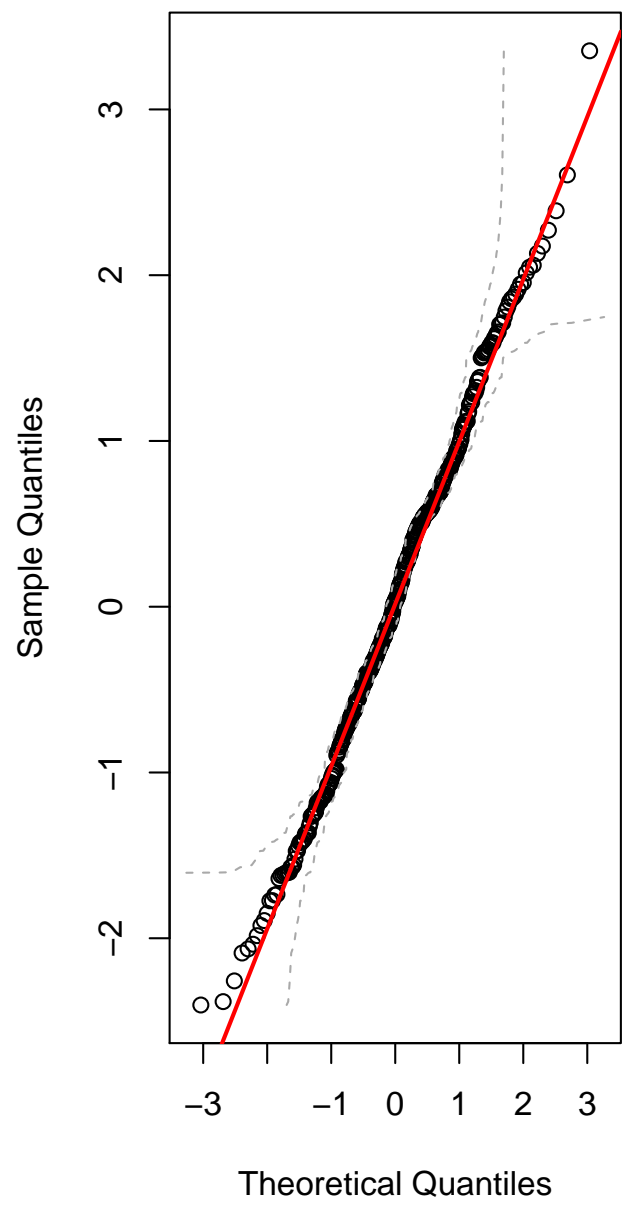

\section{Analytical Derivatives}

The first partial derivative of the Log-Likelihood function with respect to $\theta$ is the score function. Let $\eta_{i j}, \eta_{i k} \in\left\{\epsilon_{i}, \lambda_{i}, \sigma_{i}\right\}$ and $\zeta_{i}=\left(\Phi^{-1}\left(F_{1}\left(x_{i 1}\right)\right), \ldots, \Phi^{-1}\left(F_{P}\left(x_{i P}\right)\right), \Phi^{-1}\left(F_{\epsilon}\left(\epsilon_{i}\right)\right)\right)^{\prime}$ 


$$
\begin{aligned}
\frac{\partial \log L(\boldsymbol{\theta})}{\partial \eta_{i j}} & =\frac{\partial \sum_{i=1}^{n} \log L_{i}(\boldsymbol{\theta})}{\partial \eta_{i j}} \\
& =\sum_{i=1}^{n} \frac{\partial \log L_{i}(\boldsymbol{\theta})}{\partial \eta_{i j}} \\
& =\sum_{i=1}^{n} \frac{\partial \log (c(\cdot))}{\partial \eta_{i j}}+\frac{\partial \log \left(f_{\epsilon}\left(\epsilon_{i}\right)\right)}{\partial \eta_{i j}} \\
& =\sum_{i=1}^{n} \frac{1}{c(\cdot)} \frac{\partial c(\cdot)}{\partial \zeta_{i(P+1)}} \frac{\partial \zeta_{i(p+1)}}{\partial F_{\epsilon}\left(\epsilon_{i}\right)} \frac{\partial F_{\epsilon}\left(\epsilon_{i}\right)}{\partial \eta_{i j}}+\frac{\partial \log \left(f_{\epsilon}\left(\epsilon_{i}\right)\right)}{\partial \eta_{i j}}
\end{aligned}
$$

with

$$
\begin{aligned}
& \epsilon_{i}=y_{i}-\alpha_{0}-\gamma_{i j}-\sum_{d=1}^{D=2} \alpha_{d} z_{i d}-\sum_{p=1}^{P=3} \beta_{p} x_{i p} \\
& \frac{\partial \log L(\boldsymbol{\theta})}{\partial \beta_{p}}=\sum_{i=1}^{n} \frac{\partial \log L_{i}(\boldsymbol{\theta})}{\partial \beta_{p}} \\
&=\sum_{i=1}^{n} \frac{\partial \log L_{i}(\boldsymbol{\theta})}{\partial \epsilon_{i}} \frac{\partial \epsilon_{i}}{\partial \beta_{p}} \\
&=\sum_{i=1}^{n} \frac{\partial \log L_{i}(\boldsymbol{\theta})}{\partial \epsilon_{i}}\left(-x_{i p}\right)
\end{aligned}
$$

and similiarly for all $\xi \in \theta \backslash\{\lambda, \sigma, \Sigma\}$. For the matrix $\Sigma$ the number of parameters to be estimated equals $(P+1)((P+1)-1) / 2$.

$$
\begin{aligned}
\frac{\partial \log L(\boldsymbol{\theta})}{\partial \boldsymbol{\Sigma}} & =\sum_{i=1}^{n} \frac{\partial \log L_{i}(\boldsymbol{\theta})}{\partial \boldsymbol{\Sigma}} \\
& =\sum_{i=1}^{n} \frac{1}{c(\cdot)} \frac{\partial c(\cdot)}{\partial \boldsymbol{\Sigma}} \\
& =\sum_{i=1}^{n} \frac{1}{c(\cdot)}\left|\boldsymbol{\Sigma}^{-1}\right|^{-\frac{1}{2}} \exp \left\{-\frac{1}{2} \zeta_{i}^{\prime} \Sigma^{-1} \zeta_{i}\right\} \exp \left\{\frac{1}{2} \zeta_{i}^{\prime} \zeta_{i}\right\}\left(-\frac{1}{2}\left(\boldsymbol{\Sigma}^{-1}+\boldsymbol{\Sigma}^{-1}\left(\zeta_{i} \zeta_{i}^{\prime}\right) \boldsymbol{\Sigma}^{-1}\right)\right)
\end{aligned}
$$


For simplicity the index $i$ is dropped from here on.

$\frac{\partial c(\cdot)}{\partial \zeta_{(P+1)}}=\left|\Sigma^{-1}\right|^{\frac{1}{2}} \exp \left\{-\frac{1}{2} \zeta^{\prime} \Sigma^{-1} \zeta\right\} \exp \left\{\frac{1}{2} \zeta^{\prime} \zeta\right\}\left(\left(-\Sigma^{-1} \zeta\right)_{(P+1)}+\zeta_{(P+1)}\right)$

where $\left(\Sigma^{-1} \zeta\right)_{(P+1)}$ is the $P+1$ component of $\Sigma^{-1} w$

$$
\frac{\partial \zeta_{i(P+1)}}{\partial F_{\epsilon}(\epsilon)}=\sqrt{2 \pi} e^{\operatorname{erfc}^{-1}\left(2 F_{\epsilon}\left(\epsilon_{i}\right)\right)^{2}}
$$

Derivatives of $\log \left(f_{\epsilon}(\epsilon)\right):{ }^{10}$

$$
\frac{\partial \log \left(f_{\epsilon}(\epsilon)\right)}{\partial \epsilon}=\frac{\sqrt{2 \pi} \sigma e^{\frac{\epsilon^{2}}{2 \sigma^{2}}}\left(-\frac{\epsilon e^{-\frac{\epsilon^{2}}{2 \sigma^{2}} \operatorname{erfc}\left(\frac{\lambda \epsilon}{\sqrt{2} \sigma}\right)}}{\sqrt{2 \pi} \sigma^{3}}-\frac{\lambda e^{-\frac{\lambda^{2} \epsilon^{2}}{2 \sigma^{2}}-\frac{\epsilon^{2}}{2 \sigma^{2}}}}{\pi \sigma^{2}}\right)}{\operatorname{erfc}\left(\frac{\lambda \epsilon}{\sqrt{2} \sigma}\right)}
$$

$\frac{\partial \log \left(f_{\epsilon}(\epsilon)\right)}{\partial \lambda}=-\frac{\sqrt{\frac{2}{\pi}} \epsilon e^{-\frac{\lambda^{2} \epsilon^{2}}{2 \sigma^{2}}}}{\sigma \operatorname{erfc}\left(\frac{\lambda \epsilon}{\sqrt{2} \sigma}\right)}$

$\frac{\partial \log \left(f_{\epsilon}(\epsilon)\right)}{\partial \sigma}=\frac{\sqrt{2 \pi} \sigma e^{\frac{\epsilon^{2}}{2 \sigma^{2}}}\left(-\frac{e^{-\frac{\epsilon^{2}}{2 \sigma^{2}}} \operatorname{erfc}\left(\frac{\lambda \epsilon}{\sqrt{2 \sigma}}\right)}{\sqrt{2 \pi} \sigma^{2}}+\frac{\epsilon^{2} e^{-\frac{\epsilon^{2}}{2 \sigma^{2}}} \operatorname{erfc}\left(\frac{\lambda \epsilon}{\sqrt{2} \sigma}\right)}{\sqrt{2 \pi} \sigma^{4}}+\frac{\lambda \epsilon e^{-\frac{\lambda^{2} \epsilon^{2}}{2 \sigma^{2}}-\frac{\epsilon^{2}}{2 \sigma^{2}}}}{\pi \sigma^{3}}\right)}{\operatorname{erfc}\left(\frac{\lambda \epsilon}{\sqrt{2} \sigma}\right)}$

\footnotetext{
${ }^{10} \operatorname{erf}(\cdot)$ denotes the error function; $\operatorname{erfc}(\cdot)$ denotes the complementary error function.
} 
Derivatives of $F_{\epsilon}(\epsilon)$ :

$$
\begin{aligned}
& \frac{\partial F_{\epsilon}(\epsilon)}{\partial \epsilon}=\frac{\sqrt{\frac{2}{\pi}} e^{-\frac{\epsilon^{2}}{2 \sigma^{2}}} \mathcal{T}\left(\frac{\epsilon}{\sigma}, \lambda\right)}{\sigma}-\frac{e^{-\frac{\epsilon^{2}}{2 \sigma^{2}}} \operatorname{erfc}\left(-\frac{\epsilon}{\sqrt{2} \sigma}\right) \operatorname{erf}\left(\frac{\lambda \epsilon}{\sqrt{2} \sigma}\right)}{2 \sqrt{2 \pi} \sigma} \\
& \frac{\partial F_{\epsilon}(\epsilon)}{\partial \lambda}=\frac{\operatorname{erfc}\left(-\frac{\epsilon}{\sqrt{2} \sigma}\right) e^{-\frac{\left(\lambda^{2}+1\right) \epsilon^{2}}{2 \sigma^{2}}}}{2 \pi\left(\lambda^{2}+1\right)} \\
& \frac{\partial F_{\epsilon}(\epsilon)}{\partial \sigma}=\frac{\epsilon e^{-\frac{\epsilon^{2}}{2 \sigma^{2}}} \operatorname{erfc}\left(-\frac{\epsilon}{\sqrt{2} \sigma}\right) \operatorname{erf}\left(\frac{\lambda \epsilon}{\sqrt{2} \sigma}\right)}{2 \sqrt{2 \pi} \sigma^{2}}-\frac{\sqrt{\frac{2}{\pi}} \epsilon e^{-\frac{\epsilon^{2}}{2 \sigma^{2}}} \mathcal{T}\left(\frac{\epsilon}{\sigma}, \lambda\right)}{\sigma^{2}}
\end{aligned}
$$





\title{
Chapter 3
}

\section{Do Labor Market Institutions affect Productivity? \\ Evidence from Regionally Aggregated Data}

\begin{abstract}
This essay extends the literature on the productivity effects of countryspecific labor market institutions by means of a semiparametric production function approach to 191 European regions (NUTS-2) over the period from 1995 to 2008. Rather than focusing exclusively on one particular institution progress is made by examining the effects of a whole set of labor market characteristics. The results indicate that stronger presence of unions, higher firing costs and more generous unemployment benefit payments tend to have detrimental marginal productivity effects. Our findings on heterogeneous productivity effects from higher bargaining coverage rates suggest that wage bargaining systems play a key role in determining the direction of the effect. For countries with higher degrees of centralization of wage bargaining an increase in the coverage rate leads to a fall in regional productivity. While higher coverage promotes regional productivity in countries with more decentralized bargaining systems.
\end{abstract}

This chapter is a joint work with Hannes Greve. The data set employed in this paper was used previously for the master's thesis of Oliver Ken Haase. Some introductory parts and parts from the literature review of the master' thesis were adopted for chapter 3.1 \& chapter 3.2. The methodology has undergone a fundamental change and is considerably more sophisticated in this work. The master's thesis was also kindly uploaded to turnitin.com by Professor Stan du Plessis from the Stellenbosch University.

Acknowledgements: We acknowledge comments from Helmut Herwartz and Xiaohua Yu. Helmut Herwartz also kindly provided the data set for this work.

Author contributions: Haase O.K conceptualised the idea, carried out the analysis and wrote the paper. Greve H. provided research guidance and revised the paper. 


\subsection{Introduction}

The economic literature refers to labor market institutions as a set of formal rules which influence the interaction of supply and demand on labor markets and, as a corollary, the price of labor that emerges from that interaction. The conventional view is that labor market institutions are distortive and prevent markets from optimal outcomes by raising the price of labor and reducing the probability of dismissals impeding employment adjustments according to firms' requirements. Starting back in the 1980s, labor market institutions have continuously been pointed out to be the factors behind the differences in unemployment rates between the relatively more flexible labor markets of the US and the UK, and the more regulated labor markets of continental Europe (Nickell, 1997). The release of the OECD Jobs Study in 1994 manifested the consensus that relatively higher unemployment in Europe is to be seen as the consequence of generous unemployment benefits and strong labor unions. Further impetus for more labor market flexibility was represented by the introduction of the currency union in 1999 which assigned labor markets the macroeconomic role to ease off pressures from asymmetric shocks by means of quick employment adjustments. Subsequent research on this matter showed that stronger institutions prolong the adverse effects of shocks on employment and largely determine the speed of economic adjustments during the post-shock period (Blanchard and Wolfers, 2000). Recent labor market reforms in Europe were intended to create a "good mix" between flexibility and job security through broadening of the scope for temporary employment contracts while maintaining strict employment protection for permanent contracts. A number of studies have shown that labor market reforms which introduce flexibility at the margin have only temporary employment effects with potentially negative effects on productivity (Boeri and Garibaldi, 2007; Angeles Diaz-Mayans and Sanchez, 2004; Dolado and Stucchi, 2008).

So far less attention has been paid to the relation between institutions and output performance and especially to the link between institutions and productivity. Albeit this area has garnered some attention, theoretical predictions are as mixed as the empirical evidence. Our overriding interest is in the proposition that labor market institutions affect regional productivity in Europe. For this purpose we apply a two-stage analysis. In the first stage, the region-level production technology is estimated for which we correct for possible endogeneity due to unobserved productivity components. 
Controlling for time-invariant regional effects, annual common shocks and spatial dependence, productivity effects of country-specific labor market institutions are indentified in the second stage. To our knowledge this essay is the first to subject the effects of various labor market institutions on productivity to an empirical testing by means of a semiparametric estimation procedure. For this purpose we employ a data set covering 191 regional economies (NUTS-2) of 14 European countries over the period of 14 years (1995-2008). We consider three sets of labor market institutions using four indicators of institutional forces in order to measure their impact on total factor productivity. These indicators are union membership, collective bargaining coverage, the OECD index of employment legislation and unemployment benefits ratios representing the benefit systems.

One peculiarity among European economies is that a large share of employees find their compensation determined by collective bargaining agreements independent of their union membership status (Layard et al., 2005). Calmfors (1993) and Layard et al. (2005) argue that an increase in collective bargaining coverage leads to a shift in the labor market towards more unionized jobs at the expense of non-unionized jobs in the long run. This will likely entail both, an increase in wages and employment in the unionized sector. Given the link between wages and productivity an increase in union coverage may give regional productivity a boost if the unionized sector is sufficiently large. Whereas a rise in union membership strengthens the bargaining power of the union as a larger fraction of the work force is now able to inflict damage on the employer via strike potentially harming productivity (Calmfors, 1993).

Our results indicate that stronger presence of unions, stricter employment rules and more generous unemployment benefit payments tend to have detrimental marginal effects on regional productivity. Further, our findings on heterogeneous productivity effects from higher bargaining coverage rates suggest that wage bargaining systems are important in determining the direction of the effect. Countries with highly centralized wage bargaining systems (i.e. Austria, Denmark and Sweden) are negatively affected by an increase in the share of the labor force covered by collective bargaining agreements, whilst higher coverage in countries with more decentralized wage setting schemes promotes regional productivity.

The remainder is organized as follows. The next section gives an overview of the literature that links productivity to labor market institutions. Section 3 introduces the data and the methodology taken up in this essay. Section 4 
presents the empirical results, and Section 5 concludes.

\subsection{Institutions and productivity}

Freeman and Medoff (1984) conclude that the overall productivity effect of unions is positive. According to their conceptual framework unions' positive effects are associated with the so called "collective voice and institutional response face", whereas the negative effects are associated with the "monopoly face" of unions. The collective voice and institutional response view claims that unions give workers an opportunity to express their dissatisfaction over current workplace conditions which could otherwise only be expressed through quitting (Hirschman, 1970). In order to avoid costly lay-offs the management may respond through improved personnel policies which manifest in higher worker motivation. More recent studies indicate that unionised plants with more integrative workplace practices have significantly higher productivity than other similar non-unionised plants (Black and Lynch, 2001; Bloom and Van Reenen, 2007; Doucouliagos and Laroche, 2006). The monopoly face view argues that unions enforce higher wages which tend to act as a tax on the returns on investment which limits firms' spendings on R\&D and tangible and intangible assets, thus hampering the adoption of productivity enhancing technologies (Connolly et al., 1986; Hirsch and Link, 1987; Link and Siegel, 2002; Lommerud et al., 2006; Menezes-Filho and Van Reenen, 2003). However, unions' wage gains may also tighten management control to minimise inefficiencies in production (Hirsch, 2003). Productivity response from higher coverage rates may also depend on the degree of centralization of wage bargaining (Calmfors and Driffill, 1988). Unions are more inclined to internalize externalities, i.e. inflation and unemployment, caused by excessive wage claims if wage bargaining is centralized (Holden and Raaum, 1991). Calmfors (1993) concludes that higher coverage rates are expected to go along with larger wage increases in the unionised sector under decentralized bargaining.

Institutions such as employment protection legislation refer to the de facto rules of employment protection which affect firms' ability to adjust labor demand by imposing costs on dismissals (Bentolila and Bertola, 1990). ${ }^{1}$ Firms may respond by choosing to retain unproductive workers instead of firing them in order to circumvent the costs associated with dismissals (Brunello

\footnotetext{
${ }^{1}$ Samaniego (2006) shows that regulations are particularly binding in industries that operate in environments characterised by rapid technological changes.
} 
et al., 2007; Di Pietro, 2002). Inefficient labor structures tend to be further reinforced if adjustment costs induce firms to amplify market related labor hoarding practices to maintain higher than required stocks of labor resulting in a reduction of hours worked and/or a reduction of work intensity (Dietz et al., 2010). Firms may also respond to adjustment costs by substituting capital for labor which potentially raises productivity. However, Autor et al. (2007) exploit the adoption of wrongful discharge protection by US state courts to estimate the effect of dismissal costs on firms productivity. Their results show that the introduction of good faith exception indeed leads firms to substitute capital for labor which raises labor productivity, but total factor productivity declines. Strict dismissal rules could result in higher productivity in the advent of an expected long-term tenure. Workers are then incentivised to increase effort or to acquire new skills and firms may be more inclined to provide training as it becomes quasi contractable (Belot et al., 2007; Koeniger, 2005). However, this effect might be offset if employment protection is associated with a decreased risk of discharge and the lower threat of dismissal might incentivise shirking or to be frequently absent. ${ }^{2}$

Passive labor market policies such as unemployment benefits first of all reduce the opportunity costs of being unemployed, thereby raising reservation wages and inducing lower search effort (Brown and Koettl, 2015). Productivity may be negatively affected if workers exert lower on-the-job effort due to the improved outside option given that monitoring is imperfect (Shapiro and Stiglitz, 1984). Productivity may also decrease ex-ante, i.e. before the job has been chosen, if reduced job search results in fewer matches between job-seekers and vacancies.

\subsection{Data and estimation strategy}

\subsubsection{Country and region specific characteristics of European labor markets}

The analysis draws on annual data for the period 1995 to 2008 for 191 regional economies of 14 European countries. The countries are Austria (at), Belgium (be), Germany (de), Denmark (dk), Spain (es), Finland (fi), France (fr), Greece (gr), Ireland (ie), Italy (it), Netherlands (nl), Portugal (pt), Sweden

\footnotetext{
${ }^{2}$ Ichino and Riphahn (2005) show that workers in the probation period are increasingly absent as soon as they foresee to be transferred to permanent contracts covered by employment protection.
} 
(se) and the United Kingdom (uk). Output is measured by real gross value added. The information on employment and capital stocks aggregated across all sectors is obtained from the European regional database of Cambridge Econometrics which in turn draws upon the EUROSTAT Regio database and official data from national providers.

We distinguish four factors that characterise country specific labor market institutions. Corresponding information on labor market institutions are the standard OECD indicators. Variables referring to two different aspects of wage determination constitute union density or unionisation rate measured by the share of union members from the labor force and collective bargaining coverage measured by the share of the labor force covered by collective agreements negotiated between unions and employers. The latter is obtained from the Amsterdam Institute for Advanced Labor Studies. The index of employment protection legislation reflects the strictness of the de facto (i.e. the formal and informal) job protection rules. The ratio of unemployment benefits a worker receives relative to his last gross income represents the benefit system. Region specific shares of employment across four sectors (i.e. agriculture, construction, manufacturing, service) are considered in the first stage of the estimation procedure to control for some of the heterogeneity of regional technologies.

Panels of figure 1 display the spatial distribution of measures of the country specific institutional proxies. Denmark granted the largest benefits whereas Greece had the least generous replacements (around 15\%). Sweden shows the highest union density with $83 \%$ of its labor force being union members. Union membership is relatively high among Scandinavian countries as membership is a requirement for benefits eligibility. In Austria almost the entire labor force's compensation is collectively bargained while the costs involved in dismissing individuals are the highest in Portugal. 
FIGURE 2.1: Spatial distribution for labor market institutions

(a) Unionisation rate

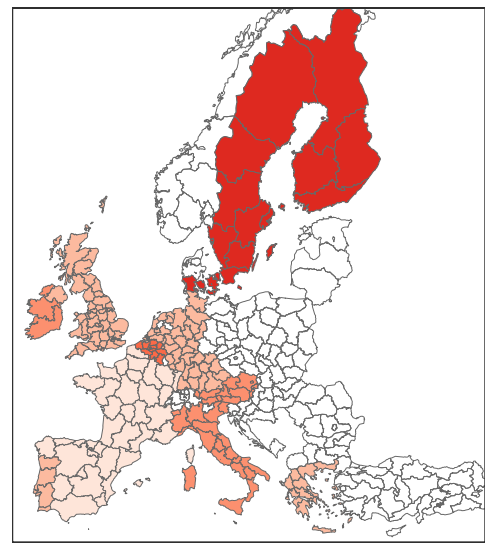

(c) Unemployment benefits ratio (\%)

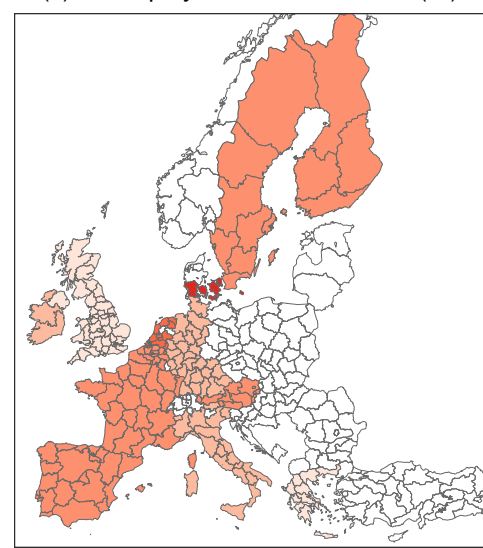

(b) Collective bargaining coverage rate

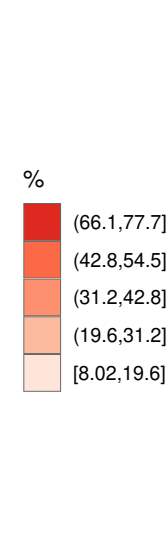

$\%$

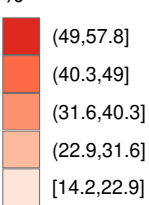

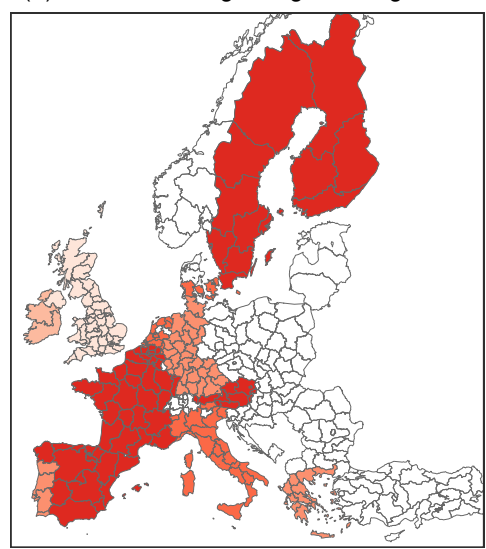

$\%$

$(86,98.7]$ $(73.3,86]$ $(60.6,73.3]$ $(48,60.6]$ [35.3,48]

(d) OECD index of employment protection

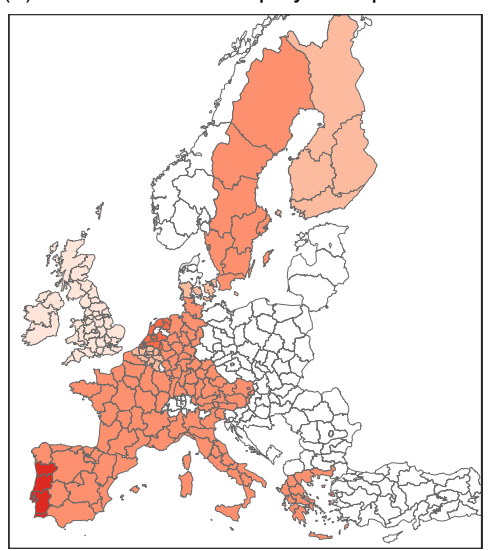

Scores

$(3.96,4.52]$ $(2.83,3.4]$ $(2.27,2.83]$ $(1.7,2.27]$ $[1.14,1.7]$

\subsubsection{Productivity}

Before we examine correlations between labor market institutions and productivity, we first estimate a production function and use the estimated parameters to recover region-specific and time-varying measures of productivity. We also control for regional sectoral allocation of labor by considering these as shifters of the common production technology. Productivity shocks observed by firms affect the accumulation of inputs within the regions and lead to biased ordinary least squares (OLS) estimates of input coefficients. Thus, we maintain a parametric specification of the production function, but choose a nonparametric representation of productivity to impose a structure on the decision-making process of the underlying firms (Olley and Pakes, 1996). In this essay, we use the Ackerberg et al. (2015) (henceforth ACF) refinement of Olley and Pakes (1996) (henceforth OP). ACF suggest that the OP approach most likely suffers from multicollinearity issues due to separate identification of input parameters. A brief description of the approach is provided in the Appendix. 
The production function to be estimated reads as:

$$
\begin{aligned}
y_{i t} & =\beta_{0}+F\left(x_{i t}\right)+\text { shares }_{i t} \theta+\omega_{i t}+\eta_{i t}, \\
i & =1, \ldots, N ; t=1, \ldots, T .
\end{aligned}
$$

where $N$ is the cross-section of regions operating over a fixed time dimension $T, y_{i t}$ is the mean scaled and logged output of the $i$-th region at time $t$. The common intercept parameter $\beta_{0}$ represents mean efficiency. $\mathrm{A}(2 \times 1)$ vector of mean scaled and logged input quantities that consist of the regional stock of capital and employment is denoted by $x_{i t}$. Due to the level of aggregation, a Cobb-Douglas specification is often used which may involve the assumption of constant returns to scale. We use the flexible translog specification (Christensen, 1971) which allows returns to scale to vary at every point in the sample. The technology is represented by $F\left(x_{i t}\right)=x_{i t} \delta+\frac{1}{2} x_{i t}^{\prime} \Psi x_{i t}$, where $\delta$ is a $(1 \times 2)$ vector of parameters and $\Psi$ is a $(2 \times 2)$ matrix of parameters to be estimated. Furthermore, the $(3 \times 1)$ vector shares ${ }_{i t}$ accommodates sectoral labor allocations with its parameters contained in the $(1 \times 3)$ vector $\theta$ to be estimated. Uninformative noise is captured by $\eta_{i t}$, whereas $\omega_{i t}$ represents a structural unobservable associated with productivity.

We produce two sets of estimates. For the first set, we estimate the production function as in (1) to obtain output elasticities of inputs. For the second, we estimate the input coefficients by OLS for the sake of comparison. Table 1 displays parameter estimates for our translog specification of the production function. As expected, all technology parameters are biased with OLS if input choice is correlated with productivity shocks. With respect to the functional form the translog specification including squared and crossed terms yields consistent estimation results. Positive marginal returns with respect to both input factors and negative coefficients for both squared terms measured at the mean fulfill the monotonicity condition which requires a production function to be monotonic and concave in input quantities. In addition, the positive estimate for the crossed term indicates a complementary relation between capital and labor.

Total factor productivity of region $i$ at time $t$ can then be recovered as residual according to

$$
\text { tf } p_{i t}=y_{i t}-x_{i t} \widehat{\delta}-\frac{1}{2} x_{i t}^{\prime} \widehat{\Psi} x_{i t}-\text { shares }_{i t} \widehat{\theta}
$$


TABLE 2.1: Output elasticities of the translog production function

\begin{tabular}{lcc}
\hline & OLS & OP w / ACF \\
\cline { 2 - 3 } Dependent variable: & $\mathrm{y}_{i t}$ & $\mathrm{y}_{i t}$ \\
\hline Labor & $.579^{* * *}$ & $.583^{* * *}$ \\
Capital & $.013)$ & $(.000)$ \\
& $.417^{* * *}$ & $.422^{* * *}$ \\
Labor $\times$ Labor & $.012)$ & $(.000)$ \\
& $-.178^{* * *}$ & $-.084^{* * *}$ \\
Capital $\times$ Capital & $.035)$ & $(.000)$ \\
Labor $\times$ Capital & $.309^{* * *}$ & $-.150^{* * *}$ \\
& $(.031)$ & $(.000)$ \\
Manufacturing & $.233^{* * *}$ & $.238^{* * *}$ \\
Service & $(.032)$ & $(.000)$ \\
& $.021^{* * *}$ & $.026^{* * *}$ \\
Construction & $.008)$ & $(.000)$ \\
Observations & $.323^{* * *}$ & $.329^{* * *}$ \\
& $(.017)$ & $(.000)$ \\
\hline
\end{tabular}

Notes: Robust clustered standard errors in parentheses. ${ }^{* * *},{ }^{* *},{ }^{*}$ denote significance at $1 \%, 5 \%$ and $10 \%$ respectively. Intercepts included but not reported. The dependent variable is gross value added.

TFP measures obtained from equation (2) may reflect differences in markups and the number of multiproduct firms within regions (Klette and Griliches, 1996; Katayama et al., 2009; De Loecker and Konings, 2006; De Loecker, 2011; Van Beveren, 2012). With regional fixed effects in the next step, our estimates control for cross-sectional differences in productivity that may be caused for instance by differences in the number of firms or work ethics. Thereby we consider exclusively within variations and not variations in the levels of institutional proxies.

\subsubsection{Labor market institutions}

For the second stage, we use total factor productivity obtained in (3.2) to estimate the productivity effects of labor market characteristics using a fixed effect spatial lag model (SAR model) to also account for regional externalities (Kosfeld and Dreger, 2006). The second-stage model reads as:

$$
t f p_{i t}=\rho \sum_{j} w_{i j} t f p_{j t}+\alpha_{i}+\tau_{t}+z_{i t} \gamma+e_{i t}
$$


where $t f p_{i t}$ is the logged total factor productivity estimate derived from the first stage, $\alpha_{i}$ captures time-invariant region-specific effects, and $\tau_{t}$ denotes a common time effect. The variables of interest, i.e. proxies for labor market characteristics, are comprised by the vector $z_{i t}$, where $\gamma$ is the vector of productivity parameters to be estimated. $w_{i j}$ depicts the pattern of spatial dependence based on the inverse distance between the centroids of region $i$ and region $j$. Spatial dependence is quantified by means of the spatial autoregressive parameter $\rho$ restricted to be less than unity in absolute value. $e_{i t}$ is a normally distributed i.i.d. disturbance with constant variance. We estimate the model with spatially autoregressive productivity and fixed effects using the quasi-ML estimator derived by Lee and Yu (2010).

\subsection{Results}

Table 2 displays the parameter estimates for the institutional effects. We include unemployment benefit ratios and the index of employment protection legislation among all specifications. Results indicate that more generous unemployment benefits tend to negatively affect regional productivity. The magnitude of the effects remains largely unchanged across specifications. The coefficient on employment protection is significantly negative across all specifications which supports the idea that firing costs act as a constraint on the reallocation of labor towards more productive activities possibly reinforcing the problem of quality and quantity mismatch.

In column (1) we control for collective bargaining coverage. The positive and significant coefficient on collective bargaining coverage may confirm Freeman and Medoff (1984)'s positive "voice effect" which precipitates better workplace policies and improves communication channels between management and employees. On the other hand, a positive productivity response from higher collective bargaining coverage due to wage increases in the unionised sector may also be supported by efficiency wage considerations.

In column (2) we introduce union membership instead of collective bargaining coverage. The exchange in the variable hardly affects the magnitude of the other coefficients. The low and insignificant effect of higher union density most likely reflects an omitted variable bias due to overlaps between union membership and collective bargaining coverage. 
TABLE 2.2: The effect of labor market institutions on regional productivity

\begin{tabular}{|c|c|c|c|c|}
\hline Dependent variable: $t f p_{i t}$ & (1) & $(2)$ & (3) & (4) \\
\hline Union membership rate & & $\begin{array}{c}-.004 \\
(.013)\end{array}$ & $\begin{array}{c}-.032^{* *} \\
(.015)\end{array}$ & $\begin{array}{c}-.035^{* *} \\
(.015)\end{array}$ \\
\hline Coverage rate & $\begin{array}{l}.077^{* * *} \\
(.024)\end{array}$ & & $\begin{array}{l}.105^{* * *} \\
(.027)\end{array}$ & $\begin{array}{l}.123^{* * *} \\
(.027)\end{array}$ \\
\hline Coverage rate $\times$ centralization dummy & & & & $\begin{array}{c}-.663^{* * *} \\
(.147)\end{array}$ \\
\hline Unemployment benefits ratio & $\begin{array}{c}-.022^{* *} \\
(.009)\end{array}$ & $\begin{array}{c}-.022^{* *} \\
(.008)\end{array}$ & $\begin{array}{c}-.022^{* *} \\
(.009)\end{array}$ & $\begin{array}{c}-.022^{* *} \\
(.009)\end{array}$ \\
\hline EPL index & $\begin{array}{c}-.075^{* * *} \\
(.024)\end{array}$ & $\begin{array}{c}-.093^{* * *} \\
(.025)\end{array}$ & $\begin{array}{c}-.084^{* * *} \\
(.025)\end{array}$ & $\begin{array}{c}-.088^{* * *} \\
(.025)\end{array}$ \\
\hline Observations & 2,674 & 2,674 & 2,674 & 2,674 \\
\hline
\end{tabular}

Notes: Robust clustered standard errors in parentheses. ${ }^{* * *}, * * *$ denote significance at $1 \%, 5 \%$ and $10 \%$ respectively. Intercepts included but not reported. All estimations include dummies for each region and year and take account of spatial dependency.

Thus, we control for both covariates in column (3) to solve the likely issue of confounding apparent in the first two specifications between collective bargaining and union density. The positive effect from higher bargaining coverage increases in magnitude while the negative union density effect becomes significant and also increases in magnitude. The negative and significant estimate of the coefficient on union density may reveal the monopoly face of unions impeding the introduction of possibly labor saving practices. A different rationale for the negative effect might be that unions offer an exclusive good, i.e. higher job security, which possibly attracts individuals with lower employment probabilities. This self-selection scheme may represent an additional underlying cause for the negative union effect on productivity.

In column (4) we check for possible heterogeneous effects from higher coverage rates and interact the coverage rate with a dummy that takes the value of one for countries with highly centralized wage bargaining systems (i.e. Austria, Denmark and Sweden). For these, an increase in the coverage rate leads to a fall in regional productivity, whilst the reverse applies to countries with more decentralized wage bargaining systems. This finding may support the view that higher levels of centralization induce unions to internalise externalities from excessive wage claims at the cost of lower productivity across industries given the positive link between productivity and wages. 


\subsection{Concluding remarks}

This essay subjects the question whether labor market institutions affect regional productivity to an empirical investigation. Utilising European NUTS2 level data on 191 regions from 1995 to 2008, the effect of various institutional proxies on regional production are estimated by controlling for endogeneity according to Olley and Pakes (1996) \& Ackerberg et al. (2015). We cautiously conclude that our findings on the negative effects of higher unionisation on regional productivity may point at Freeman and Medoff's monopoly face of unions due to excessive wage claims enforced by costly lay-off threats and impediments to adopt new and possibly labor saving technologies. Heterogeneous effects from higher bargaining coverage on productivity could refer to the "voice effect" advocating for moderate wage increases if bargaining is more centralized at the cost of lower productivity. The positive effect for more decentralized bargaining systems may support efficiency wage views. Also, we would expect more workers with lower employment probabilities among unions. Our findings on higher employment protection confirm its role as an impediment to the maintenance of optimal labor stocks. Higher unemployment benefits are linked to lower productivity which backs up the idea that generous payments disincentivise job seeking effort or on the job effort due to shifts in reservation wages.

Based on the idea that unions tend to arise in the wake of higher economic activity we suggest that labor market policies should obviously be heterogeneous across regions conditional on regional productive performance. A onesize-fits-all approach most likely hampers the potentially desired catchingup process of low performing regions which could benefit from greater flexibility. However, exogenous interventions to induce more flexibility may give rise to higher union membership rates and strikes even though this relationship is not scrutinized in our analysis.

In regard to future research, a refinement would need to include a more nuanced measure for the degree of coordination since adverse productivity effects from unions might be offset by highly coordinated forms of bargaining (Nickell and Layard, 1999). Also, country specific measures on union density and collective bargaining coverage conceal regional variation, thus it would be desirable to extent the analysis based on region-level information for those institutions. Regressing regional productivity on institutional 
variables measured at the country level envokes an attenuation bias as crosscountry variation is used to approximate the "true" regional effect. As a corollary the attenuation bias drives the magnitude of effects towards zero which would imply that our findings are in fact more pronounced. 


\subsection{Appendix}

Following Olley and Pakes (1996) the evolution of productivity is defined as:

$$
\omega_{i t}:=E\left(\omega_{i t} \mid \omega_{i t-1}\right)+\xi_{i t}
$$

where $E(\cdot)$ follows a first-order Markov process:

$$
E\left(\omega_{i t} \mid \omega_{i t-1}, \omega_{i t-2}, . ., \omega_{i 1}\right)=E\left(\omega_{i t} \mid \Omega_{i t-1}\right)=E\left(\omega_{i t} \mid \omega_{i t-1}\right),
$$

where $\Omega_{i t-1}$ represents the information set at period $t-1$ that contains all past realizations of productivity. The unanticipated shock component $\xi_{i t}$ is independent of the productivity in $t-1$. Therefore expectations about future productivity depend only on the productivity in the previous period.

The fundamental idea of the Olley and Pakes (1996) approach to estimate productivity is that unobserved productivity is a function $f(\cdot)$ of observables:

$$
\omega_{i t}=f_{t}\left(k_{i t}, l_{i t}, I_{i t}\right) \text {, }
$$

where $l_{i t}$ is the log of the labour input, $k_{i t}$ is the log of the stock of capital and $I_{i t}$ is the log of investment.

Labor is chosen sometime before $t$ due to labor market institutions causing sluggish employment adjustments (Ackerberg et al., 2015). The stock of capital is chosen in $t-1$. Investments are made instantaneously in $t$ and expose the information on productivity.

By substituting (2.5) for $\omega_{i t}$, the production function in (1) can be written as:

$$
y_{i t}=\Phi_{i t}\left(k_{i t}, l_{i t}, I_{i t}\right)+\eta_{i t}
$$

with

$$
\Phi_{i t}=\beta_{0}+F\left(x_{i t}\right)+f_{t}(\cdot) \text {. }
$$

And, equation (2.6) is estimated in the first-stage using non-parametric techniques for $f_{t}(\cdot)$ which gives:

$$
\widehat{\Phi}_{i t}=\beta_{0}+F\left(x_{i t}\right)+\widehat{\omega}_{i t} .
$$


Parameters for the stock of capital and labor input will be jointly identified because of the inclusion of capital in $f_{t}(\cdot)$ and collinearity between labour and productivity (Ackerberg et al., 2015). ${ }^{3}$ The following moment conditions for the estimation of productions function coefficients in the second stage emerge from the assumptions underlying the evolution of productivity and the timing of the choice of inputs:

$$
E\left[\begin{array}{l}
\xi_{i t} k_{i t} \\
\xi_{i t} l_{i t}
\end{array}\right]=0
$$

Note that both moment conditions hold if $k_{i t}$ and $l_{i t}$ are decided at any time before $\mathrm{t}$ given $E\left[\xi_{i t} \mid I_{i t-b}\right]=0$ and $k_{i t}, l_{i t} \in I_{i t-b} \quad$ with $\quad b \in \mathbb{N} . I_{i t-b}$ is the information set of firms in region $\mathrm{i}$ at $t-b$.

\footnotetext{
${ }^{3}$ Separate identification as in Olley and Pakes (1996) would refer to very specific data generating processes and most likely suffers from multicollinearity issues.
} 


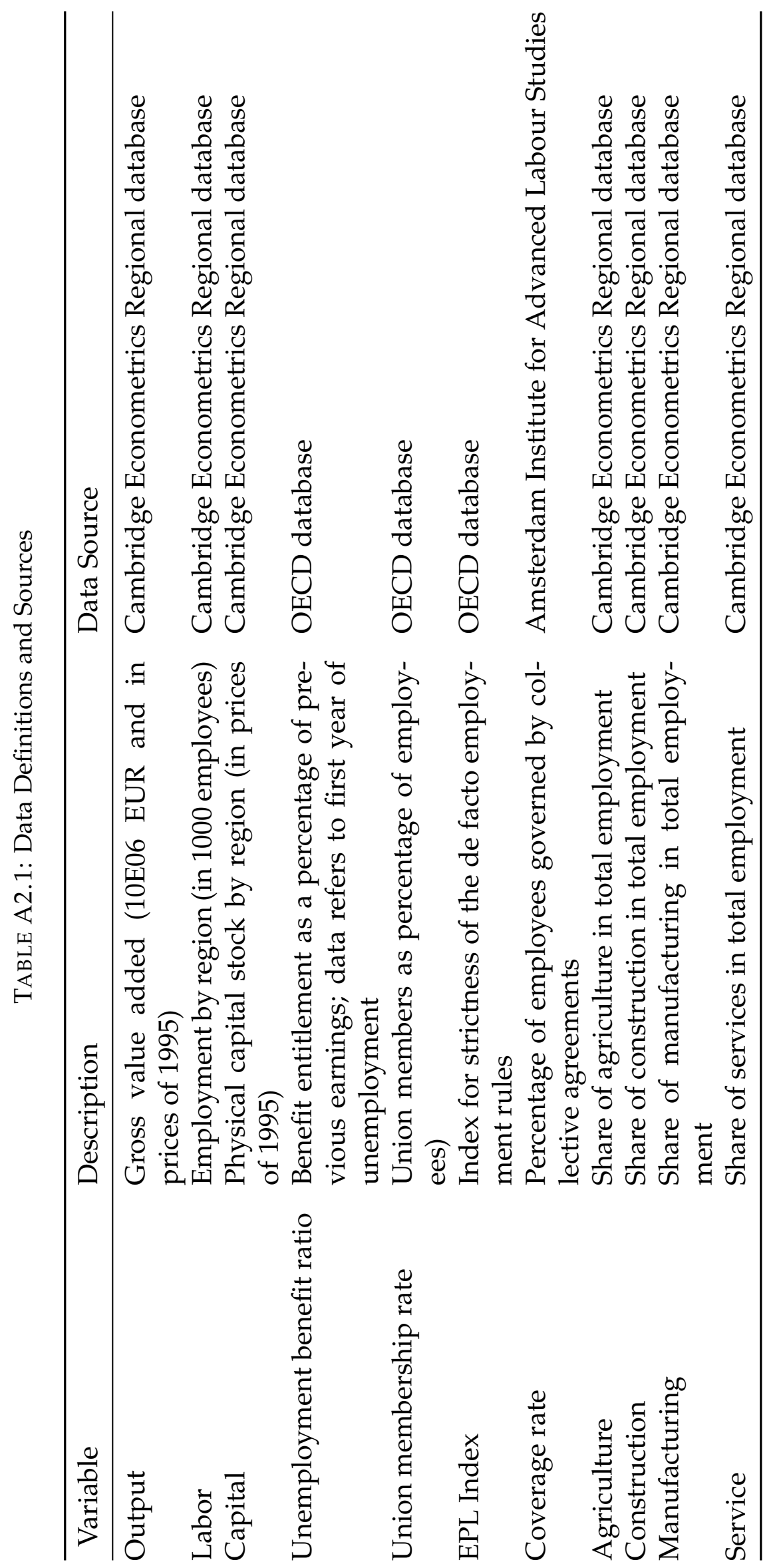





\title{
Chapter 4
}

\section{The heterogeneous effects of standards}

\section{on agricultural trade flows}

\begin{abstract}
This article uses a theory-founded translog gravity model to investigate the heterogeneous effects of food standards on aggregate agricultural trade. We revisit the "standards-as-barriers-to-trade" debate with a distinctive twist. In contrast to existing works, we show that standards reduce trade but even more so for countries that trade smaller volumes. Our identification strategy exploits the within country variation in specific trade concerns. We confirm that stricter importer standards are indeed trade-restrictive. However, the estimated trade cost elasticity varies depending on how intensively two countries trade; specifically decreasing in magnitude with increasing import share of the exporter in the importing country's total imports. The reason is simple but intuitive; bigger trading partners find it more profitable to invest in meeting the costs of importer-specific standards. This work is novel in showing that the standards-trade debate misses out on an important heterogeneity driven by existing import shares. Liberalising NTMs will favour smaller trading partners more than well-established ones.
\end{abstract}

This chapter is a joint work with Dela-Dem Doe Fiankor. Acknowledgements: We acknowledge comments from Florian Unger.

Author contributions: Fiankor D.-D.D conceptualised the idea, carried out the analysis and wrote the paper. Haase O.K derived the econometric model, provided research guidance and revised the paper. 


\subsection{Introduction}

"Food regulations in different countries are often conflicting and contradictory. Legislation governing [...] acceptable food standards often varies widely from country to country. New legislation not based on scientific knowledge is often introduced. [This] conflicting nature of food regulations may be an obstacle to trade in foodstuffs between countries (WHO, 1950; pg. 24)"

Custom tariffs and other traditional trade barriers have been negotiated down to near-zero. Concurrently, we have seen a surge in standard-like non-tariff measures (NTMs). So while it may look like countries are substituting tariff protection for NTMs, such simple arguments ignore the potential consumer or societal benefits that NTMs induce, e.g., reducing information asymmetry, mitigating consumption risks and enhancing sustainability (Orefice, 2017; Beverelli et al., 2019). However, NTMs can indeed also be protectionist, or their associated costs may keep non-compliers out of global value chains. It is often challenging to know if a particular regulation serves genuine public interests or protectionist objectives because both motives are often combined in a single measure (Swinnen, 2016). Theoretically, the direction of the standards-trade effect is ambiguous. Thus, how standards affect trade and welfare remain empirical questions. The result is the almost unending "standards as barriers or catalysts to trade" debate.

However, one thing is certain; public mandatory standards set by national governments usually vary across countries and often tend to hinder agricultural trade. They do this by increasing the cost of trading. As our opening quote suggests, this knowledge is as old as the first meeting of the Joint FAO/WHO Expert Committee on Nutrition in 1950. Recent empirical findings, e.g., public standards decrease the probability of trade (Ferro et al., 2015; Crivelli and Gröschl, 2016), and reduce both the value of trade conditional on exports (Disdier et al., 2008; Fernandes et al., 2019; Curzi et al., 2020; Kinzius et al., 2018) and the number of varieties traded (Fiankor et al., 2019), also reveal that we have made little, if any progress, in addressing the negative effects of this regulatory heterogeneity across countries. ${ }^{1}$ Using the case of public mandatory food standards, we revisit this policy-relevant debate, but with a distinctive twist. Existing studies on the standards-trade effect share

\footnotetext{
${ }^{1}$ On the other hand, by harmonising standards across countries, private voluntary standards established by retailers, e.g., GlobalGAP standards or the International Featured Standards, enhance trade (see, e.g., Ehrich and Mangelsdorf, 2018; Andersson, 2018; Fiankor et al., 2020).
} 
one thing in common; they are estimated using gravity equations that impose the limiting assumption that the elasticity of trade with respect to trade costs is constant, e.g., in the classical Anderson and Van Wincoop (2003) model, the trade cost elasticity is $1-\sigma$, where $\sigma$ denotes the elasticity of substitution. This feature means that food standards have the same proportionate effect on trade regardless of ex ante trade levels. For example, consider the point estimate of -0.15 in Disdier et al. (2008). This means that for OECD member states the introduction a new standard decreases imports by $14 \%$ regardless of the origin of the product. Even if some studies go further to assess the trade effects by income status of the exporting countries, they estimate a uniform effect for the country groups. We challenge these "one-size-fits-all" conclusions and instead show that the negative effect of standards on trade flows decreases in magnitude with increasing import share of the exporter in the importing country's total imports. The reasoning is simple; bigger trading partners find it more profitable to invest in meeting importer-specific standards.

The main objective of our study is to examine the heterogeneous effects of food standards on agricultural trade at the aggregate level. To test our hypothesis, we combine theoretical predictions from the heterogeneous firms' literature (Melitz, 2003; Helpman et al., 2008) with a theory-founded translog gravity model Novy (2013) estimated at the country level. This is one of the first applications of the translog gravity framework in the agricultural trade literature. ${ }^{2}$ Our empirical analysis exploits data on the cross-country differences in Sanitary and PhytoSanitary (SPS) standards using a panel of aggregate agricultural trade flows (HS01-HS24) between 66 importing and exporting countries over the period 1998 to 2017. Because we focus in this paper on standards that are trade restrictive, our measure of standards is from the specific trade concerns (STC) database. It records any concerns raised at the WTO against an SPS standard introduced by an importing country. If an exporter raises an STC on an SPS measure imposed by an importer, it is obvious that the former considers that particular measure to be overly stringent or even protectionist. This is particularly relevant for agricultural sector where about $94 \%$ of STCs related to SPS measures apply (WTO, 2012). Our main finding is that there is a significant heterogeneity underlying the "standardsas-barriers" argument that goes beyond the developed-developing country

\footnotetext{
${ }^{2}$ In the international trade literature, the translog gravity model has been employed to study the heterogeneity of the custom unions effect (Chen and Novy, 2018). In agricultural trade, Meng et al. (2018) use the translog gravity model to assess China's agricultural tradecost elasticity and to analyze its heterogeneity across different types of trading partners.
} 
story. Bilateral import shares matter and play an important role in moderating the trade effects of food standards. One policy implication is that NTM liberalisation will favour smaller trading partners more than well-established trading relationships.

We contribute three main novelties to the existing standards and trade literature. First, is to the empirical literature that assesses the standards-trade effect using the gravity model (Disdier et al., 2008; Ferro et al., 2015; Crivelli and Gröschl, 2016). Like many demand-side theoretical gravity equations, the models estimated in this literature assume constant elasticity of substitution (CES) expenditure functions (e.g., Anderson and Van Wincoop, 2003). This class of models limits the elasticity of trade to changes in standards to be a constant. Another implication of the CES model is that some volume of the product is purchased no matter how high the selling price. Hence, it is not straight forward to justify zero trade observations, unless we assume fixed costs of exporting on the supply side (e.g., Helpman et al., 2008). In this paper, we overcome these limitations by using a much more flexible translog functional form of the gravity model (Novy, 2013) that addresses the issue of zero trade observations while also allowing for variable trade cost elasticities. Armed with this new framework, we find empirical results consistent with the predictions of our model that the negative effects of standards decrease depending on how much two countries trade with each other. As a form of sensitivity analysis, we show that even with a standard CES gravity equation, the negative trade effects of standards decrease with increasing trade volumes. Extensions of our modelling approach allow us to show countrypair specific estimates of the introduction of an SPS measure for which an STC is raised. Our analysis is the first to present country-pair-specific effects of imposing stricter food safety standards across a panel of bilateral trade relations. ${ }^{3}$ Our contribution is important from both an analytical ${ }^{4}$ and a public policy point of view; working with country-pair specific estimates of a trade policy shock - instead of the usual average effect across all country-pairs will enhance evidence-based policy-making in the agricultural sector.

Second, our work is closely related to the literature on the heterogeneous effects of standards across firms depending on their sizes. Much of this work has been done at the firm level. Fontagné et al. (2015) show using a panel of

\footnotetext{
${ }^{3}$ Anders and Caswell (2009) provide estimates of the country-specific impacts of stricter food safety standards across a panel of bilateral trade relations with the US as an importer.

${ }^{4}$ As James Anderson argues "more general translog treatments [of the gravity model] are feasible and desirable" (Anderson, 2011; pg. 147).
} 
French exporting firms that restrictive SPS measures in the importing country decrease both the extensive and the intensive margin of trade, but these negative effects are mitigated for larger firms. Fernandes et al. (2019) show that smaller exporting firms are more affected in their market entry and exit decisions by the relative stringency of destination standards than larger exporters. Using data on Peruvian firms, Curzi et al. (2020) show that larger firms are less affected by specific trade concerns. At the macro-level, few studies have considered the heterogeneous effects of standards in terms of export volume. The exceptions include Anders and Caswell (2009) who find that regardless of development status, leading seafood exporters generally experienced a positive HACCP effect, while most other smaller trading partners faced a negative effect. Ehrich et al. (2017) apply a quantile regression procedure within the gravity framework to show that maximum residue limits impede bilateral trade of selected agricultural products between country pairs with relatively low trade volumes but have positive trade effects at the 90th decile. Our paper differs from this literature in three respects: (i) we consider the whole agricultural sector, (ii) we define size as exporterspecific market shares in an importing country, contrary to absolute trade volumes regardless of destination as done in the existing literature (Anders and Caswell, 2009; Fontagné et al., 2015; Ehrich et al., 2017; Fernandes et al., 2019; Curzi et al., 2020) and (iii) our approach to modelling the heterogeneous standards-trade effect at the country-level is consistent with the predictions of the translog gravity framework but still yields results that are consistent with the micro-data literature.

Our third contribution is to the literature that assesses the heterogeneity of the standards trade-effect across development status of the exporting countries. These studies usually report bigger trade reducing effects for developing countries compared to developed countries. For example, considering OECD imports, Disdier et al. (2008) show that OECD exporters are not significantly affected whiles exports of developing and least developed countries are reduced by SPS/TBT regulations. Similar conclusions are reached for maximum residue limits (Xiong and Beghin, 2014; Ferro et al., 2015; Curzi et al., 2018) and HACCP standards (Anders and Caswell, 2009). While for groups, these findings may be correct, our country-pair specific estimations show that the effects are not always larger for developing countries. In fact, depending on bilateral import shares the trade effects may be smaller for developing countries relative to their developed country counterparts.

The rest of the paper proceeds as follows. Section 2 discussion of the 
translog gravity model and empirical framework. This is followed in Section 3 by a discussion of the data used in the analysis with a focus on specific trade concerns. In Section 4, we discuss the results of our model estimates and discuss our research findings. Section 6 concludes and offers policy implications.

\subsection{Empirical approach}

To guide our empirical analysis, we estimate a theory-consistent structural gravity model. The gravity model in economics was until relatively recently disconnected from the rich family of economic theory (Anderson, 2011), but can now be derived from several theoretical foundations, including the Ricardian model (Eaton and Kortum, 2002), the CES/Armington demand framework (Anderson and Van Wincoop, 2003), or models with heterogeneous firms (Melitz, 2003; Chaney, 2008; Helpman et al., 2008). Inherent in these classes of models is the limiting assumption that the elasticity of trade with respect to trade costs is constant. For instance, the trade cost elasticity is fixed at $1-\sigma$ in Anderson and Van Wincoop (2003), equal to the Pareto shape parameter, $\gamma$ in Chaney (2008) or the Frechet shape parameter, $\theta$ in Eaton and Kortum (2002). This feature means that in our specific case ceteris paribus, the presence of a food standard or an increase in its stringency has the same proportionate effect on bilateral trade regardless of existing trade levels.

Since our interest is to assess the heterogeneity of the standards-trade effect, we follow Novy (2013) and employ a flexible specification for our gravity model to allow for variable trade effects from food standards. The estimating equation is derived from a general equilibrium framework - which features multiple countries that are endowed with an arbitrary number of differentiated goods - where linear homogeneity and symmetry of parameters according to Feenstra (2003) is imposed on a translog type expenditure function. Imposing market clearance and solving for general equilibrium results, the general structural translog gravity with exporter market share as the dependent variable reads as

$$
\frac{x_{i j}}{y_{j}}=\frac{y_{i}}{y^{w}}+\gamma n_{i} \ln \left(T_{j}\right)-\gamma n_{i} \ln \left(\tau_{i j}\right)+\gamma n_{i} \sum_{s=1}^{J} \frac{y_{s}}{y^{w}} \ln \left(\frac{\tau_{i s}}{T_{s}}\right),
$$

where $x_{i j}$ denotes the bilateral trade flows in 1000 USD from exporter $i$ to importer $j$, and $y_{j}$ is the gross annual imports by $j$. The two variables 
are in levels such that the dependent variable reflects $i$ 's import share in the total of $j$ 's imports which depends on total production in the exporting country $y_{i}$, normalised by global production, $y_{w}=\sum_{j=1}^{J} y_{j}$. Import shares are further linked to the inward multilateral resistance term, $\ln \left(T_{j}\right)$, which represents a weighted average of logarithmic trade costs over trading partners of importer $j$. The number of goods produced and exported by country $i, n_{i}$, reflects a measure for the extensive margin and $\gamma$ denotes the translog parameter. The bilateral costs of trading are captured in $\tau_{i j}$. At first glance, equation (4.1) looks distinct from standard CES gravity equations (Eaton and Kortum, 2002; Anderson and Van Wincoop, 2003) since the dependent variable is measured as import shares in levels and not the log of trade. As a result, the translog gravity relationship is not log-linear in trade costs, which implies a variable trade cost elasticity. This property is what we exploit to study the heterogeneity of the standards-trade effect. Nevertheless, on second glance, equation (4.1), just like the traditional CES gravity equations relates bilateral trade to bilateral trade costs and other country-specific variables.

As the first and the last term on the right-hand side of equation (4.1) is invariant over the importing partner $j$, they can be parsimoniously captured by an exporter's fixed effect $\psi_{i}$. In the same vein, inward multilateral resistance does not vary over the exporting partner $i$ and thus can be captured by an importer's fixed effect $\lambda_{j}$. Accordingly, reformulating equation (4.1) and dividing both sides of the equation by $n_{i}$ yields the estimating equation ${ }^{5}$

$$
\frac{x_{i j} / y_{j}}{n_{i}}=-\gamma \ln \tau_{i j}+\psi_{i}+\lambda_{j}+e_{i j}
$$

Following Chen and Novy (2018), we adapt the original specification in (4.2) to specify our aggregate panel data model as follows: ${ }^{6}$

$$
\frac{x_{i j t} / y_{j t}}{n_{i t}}=-\gamma \beta^{\prime} \mathbf{w}_{i j t}+\psi_{i t}+\lambda_{j t}+\alpha_{i j}+e_{i j t} .
$$

The dependent variable is import shares per good. Imports shares are set

\footnotetext{
${ }^{5}$ An alternative estimation strategy is to maintain $n_{i t}$ on the right hand as a multiplicative factor. We prefer to divide through equation (1) by $n_{i t}$ so that all possible measurement errors associated with $n_{i t}$ are passed on to the left-hand side. This also allows us to estimate our models with the usual country-time fixed effects as is standard in the gravity literature.

${ }^{6}$ Whiles the structural gravity model can be estimated at the product level (e.g., the armignton CES model of Anderson and Van Wincoop (2003)), the translog gravity model is derived at the aggregate level. Sticking closely to the theoretical model of Novy (2013) we estimate our translog gravity equations in this paper at the aggregate level. Deriving a product-specific translog gravity model goes beyond the scope of the present paper.
} 
equal to zero when no imports in the respective destination-year are reported. ${ }^{7}$ We define the extensive margin $n_{i t}$ as a time-varying count of HS2 digit categories exported within the class of agricultural products, i.e., HS01 to HS24. ${ }^{8}$ The costs of trading $\ln \left(\tau_{i j t}\right)=\beta^{\prime} \mathbf{w}_{i j t}$ are specified as a function of different time-varying observable bilateral variables, namely specific trade concerns $\left(S P S_{i j t}\right)$, bilateral tariffs $\left(\right.$ Tariff $\left._{i j t}\right)$ and regional trade agreements $\left(R T A_{i j t}\right)$. Our variable of interest is $S P S_{i j t}$. It is a dummy variable that takes the value of 1 if an exporting country $i$ raises or supports a specific trade concern against an SPS measure than an importing country $j$ maintains in year $t$. As a result, our identification strategy exploits the bilateral variation across pairwise observations between trade flows affected by the specific trade concerns and trade flows that are not affected. To control for a range of potentially omitted variables affecting bilateral trade, country-specific time varying fixed effects, $\psi_{i t}$ and $\lambda_{j t}$, are included. They capture the size terms (i.e., the total agricultural production in country $i$, and the total expenditure by country $j$ on foreign goods), and other country-specific (un)observables (e.g " institutional quality, comparative advantages in agriculture and other unilateral trade policy measures). ${ }^{9}$ They also control for multilateral resistance terms which are necessary for proper specifications of the gravity model (Anderson and Van Wincoop, 2003; Feenstra, 2004).

The panel structure of our dataset allows us to control for time-invariant heterogeneity in equation (3) by including country pair time-invariant fixed effects, $\alpha_{i j}$. Since equation (3) is in principle a gravity equation, traditional gravity variables such as distance, contiguity and language could be included in the model in place of the country-pair fixed effects. However, the countrypair fixed effects are better measures of bilateral trade costs than the standard set of bilateral varying gravity variables (Egger and Nigai, 2015; Agnosteva et al., 2019). Furthermore, public food standards imposed by the importing countries may be endogenous to bilateral trade volumes. By including the full set of three-way fixed effects in our analysis we reduce endogeneity concerns to a large extent. Including $\alpha_{i j}$ also means we exploit fully the within country variation in our control variables. $e_{i j t}$ is the random error term,

\footnotetext{
${ }^{7}$ Depending on the countries' reporting practices, this could signify that imports were of negligible size and are therefore not reported. The reporting practices are controlled for by using an appropriate fixed- effects structure in the empirical model.

${ }^{8}$ We also use other definitions of the extensive margins as a form of robustness check. For example, the count of HS6 digit categories exported or defining the extensive margin according to Hummels and Klenow (2005). These different definitions yield qualitatively similar results.

${ }^{9}$ To deal with the high-dimensional fixed effects in our model specifications, we use the user-written commands reghdfe and ppmlhdfe (Correia, 2016) in Stata.
} 
which we cluster at the country-pair level to account for heteroskedasticity. We estimate equation (3) using ordinary least squares (OLS). Because the dependent variable is measured as market shares in levels, the OLS translog gravity model can deal with zero trade observations. Note that the elasticities in the translog gravity model are not constant between bilateral country pairs. The variable trade cost elasticity can be retraced by deriving equation (4.3) with respect to our variable of interest: ${ }^{10}$

$$
\epsilon_{i j t} \approx \frac{d \ln \frac{x_{i j t} / y_{j t}}{n_{i t}}}{d S P S_{i j t}}=-\frac{\gamma \beta_{1}}{\frac{x_{i j t} / y_{j t}}{n_{i t}}} .
$$

As we expect $\beta_{1}>0$, the magnitude of the negative food standard effect on trade flows is supposed to be larger for trade relations where the exporter only governs a smaller market share in the destination market for agricultural products.

\subsection{Data}

In many high-value markets, export success is now conditional on compliance with NTMs as export competition has shifted from prices to quality (Curzi et al., 2015). In agricultural markets SPS measures, such as food standards, are often the most important NTMs driven among other things by increasing consumer awareness of food safety, shifting liability for food safety from governments to retailers, and growing public concern for consumer and environmental protection. Even though the Codex Alimentarius Commission sets international standards, the WTO's agreement on SPS measures allows countries to set their own national standards that protect human, animal, or plant health. To prevent the abuse of this provision for protectionist intents, the national standards must be based on a scientific risk assessment, not discriminatory toward countries with similar conditions, and are minimally trade distorting. These principles are not always achieved in which case standards can be abused for mercantilist trade policy objectives. SPS measures are also the most frequently encountered NTM in agri-food trade (Grant and Arita, 2017).

\footnotetext{
${ }^{10}$ For the derivation of the elasticity with respect to food standards we simply follow the definition for elasticity (i.e. $\epsilon_{y, x}:=\frac{d y / y}{d x / x}$ ).
} 
While we are broadly focused on SPS measures in the agricultural sector, our identification strategy exploits specifically the time and country differences in specific trade concerns (STCs) raised against SPS measures maintained by an importing country. STCs are issues raised at the WTO by exporting countries affected by SPS standards, which they consider unjustified and particularly restrictive (Olper, 2016). Raising an STC is a formal mechanism by which a country can introduce a complaint against another country's SPS policies regulating imports. Standards may be barriers to trade, but can also be measures for market creation. As a result, measures which form strong barriers to trade and are motivated by protectionism-rather than preventing legitimate health risks_-are likely to be raised as a concern by other members at the WTO. ${ }^{11}$ Grant and Arita (2017) call this a 'revealed concern' approach. Likewise, we would expect legitimate measures to receive fewer complaints. Hence, we can expect that measures that exporters consider as overly restrictive will attract an STC. This nature of STCs makes them de facto restrictive and thus appropriate to study the standards-trade effect if the focus, like in our case, is on the standards-as-barriers angle (see, also Fontagné et al., 2015; Grant and Arita, 2017; Orefice, 2017; Beverelli et al., 2019; Curzi et al., 2020). Furthermore, policy-makers may have little incentive to notify their own SPS measures but all kinds of incentives to notify the unjustified barriers of their partners (Grant and Arita, 2017).

The data we use on SPS STC s come from Ghodsi et al. (2017). The original source of the data is the compilation of NTMs notified to the WTO, accessible via the Integrated Trade Intelligence Portal (I-TIP). The I-TIP provides information compiled by the WTO on all trade policy measures. One major limitation of this otherwise rich dataset is that it is not readily available in a form necessary for econometric analysis or quantitative assessment. For instance, the dataset does not follow a panel structure where NTMs are distinctly assigned to products according to product classifications such as the

\footnotetext{
${ }^{11}$ This idea that exporting countries raise STCS when NTMs imposed by an importer becomes an effective trade barrier is motivated by the timing of some STCs raised at the WTO. Orefice (2017) offers many such examples. For one, in 2003 the Chinese government raised an STC complaining about an NTM imposed by the EU that restricted the imports of natural honey from China as a food safety measure due to the presence of chloramphenicol, a toxic antibiotic. The consumers' protection aim of this NTM is clear, but its timing raises eyebrows. This concern was raised in 2003, just before the EU enlargement towards the east in 2004. Among the new EU Member States, Poland and Slovenia had in 2003 a high tariff protection on Chinese honey (applied tariff on natural honey respectively $89 \%$ and $45 \%$ ) to be necessarily reduced the year after the accession to the EU at $17.3 \%$ (EU tariff protection on honey). Hence, using STCs allow us to sort through the host of SPS measures introduced annually to identify those which likely constitute unjustified measures or significant trade barrier, as opposed to justified measures which may be of little concern to exporters.
} 
FIGURE 3.1: Increasing relevance of non-tariff measures

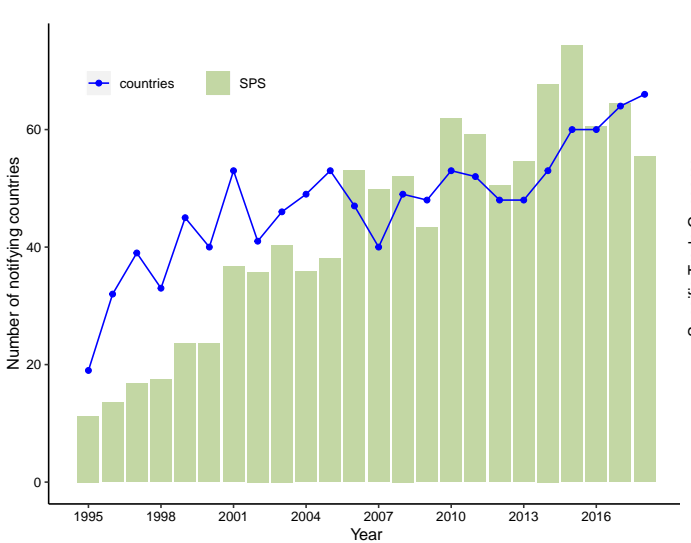

(a) SPS measures

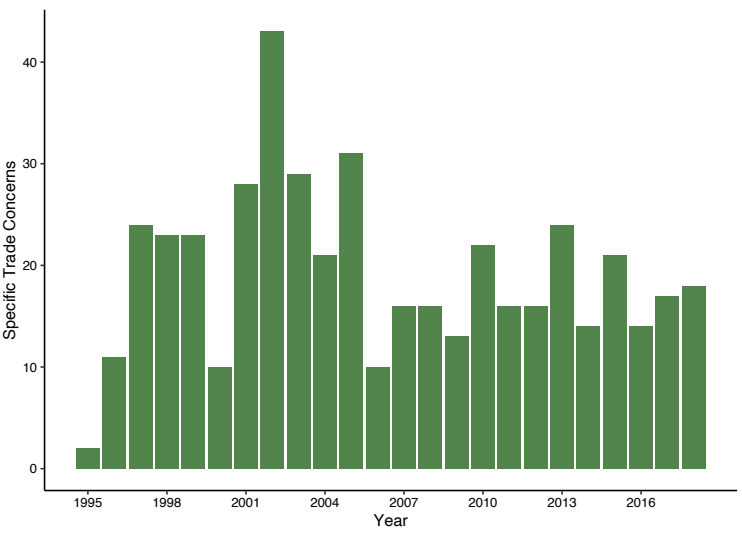

(b) Number of new STCs raised

Source: WTO I-TIP database, own graph

Harmonised System (HS) or the International Standard Industrial Classification. This limitation is addressed in Ghodsi et al. (2017). They enhance the value of the WTO I-TIP database for econometric analysis of NTMs by imputing missing product codes at the HS 6-digit level. Since we treat the agricultural sector as one unit, we aggregate this HS6 digit STCs to the country level. We limit our sample to only bilateral pairs where an STC was active at least once over the length of the panel. This brings our sample to $66 \mathrm{im}$ porting countries (including the EU15 as a group) and 66 exporting countries over the period 1998 to 2017 with a maximum of $87,120(66 \times 66 \times 20)$ observations. The list of countries in the sample are included in the appendix (Table A3.1).

While tariff rates are not hard to find, data limitations make it difficult to document general trends in the use of NTMs. For public standards, key sources of data include efforts by international organisations (e.g., UNCTAD TRAINS), non-governmental institutions, various forms of government notification to the WTO or concerns raised through firm surveys. Using data from the WTO's I-TIP database, we see a clear increasing trend in the number of SPS measures notified to the WTO and the number of countries issuing a notification (Figure 3.1a). Consequently, we also see in Figure (3.1b) that year in year out new specific trade concerns are raised on some of these notified SPS measures. If we superimpose Figure 3.1 on a graph of average tariff rates over similar time frames, it becomes clear that the rise in NTMs coincides with a fall in tariffs. Due to the conceptual difficulty of converting NTMs into their ad valorem equivalents, establishing a causal relationship between 
tariffs and NTMs has received limited attention in the literature. Empirical evidence, though scarce, confirm both substitutionary and complementary effects (Orefice, 2017; Beverelli et al., 2019). To account for this potential trade policy substitution, we control for applied tariffs in our empirical analysis.

The other standard gravity variables are derived from different sources. The bilateral trade data is taken from the Base pour l'Analyse du Commerce International (BACI) database developed by the Centre d'Etudes Prospectives et d'Informations Internationales (CEPII) which reports the bilateral value of trade by product, origin and destination (Gaulier and Zignago, 2010). The advantage of the BACI dataset over that in the UNCOMTRADE database is that the former reconciles discrepancies in bilateral trade flows between CIF import values and FOB export values. To allow us to focus on the agricultural sector, we aggregate trade data from HS01 to HS24. Tariff data comes from the World Integrated Trading System and data on regional trade agreements is taken from De Sousa (2012). Summary statistics on our dependent and control variables are reported in Table 3.1.

TABLE 3.1: Summary statistics

\begin{tabular}{lrrrrl}
\hline Variable & Mean & Std. Dev. & Min. & Max. & N \\
\hline$S P S_{i j t}$ dummy & 0.149 & 0.356 & & & 87120 \\
RTA $_{i j t}$ dummy & 0.205 & 0.403 & & & 87120 \\
Tariff $_{i j t}$ (logs) & 2.320 & 1.228 & 0 & 7.786 & 87120 \\
Import shares (\%) & 1.515 & 4.369 & 0 & 84.618 & 87120 \\
Extensive margin $\left(n_{i t}\right)$ & 23.803 & 0.904 & 15 & 24 & 87120 \\
Trade value (m USD) & 0.171 & 1.391 & 0 & 65.212 & 87120 \\
\hline
\end{tabular}

\subsection{Results and discussions}

Our baseline empirical findings are presented in Table 3.2. Columns (1) (2) present results using the OLS estimator (equation 4.3). The number of observations differ across the different estimations because in column (1) we exclude zero trade shares but include them in column (2). The high $R^{2}$ values we obtain reflect the typical good fit of gravity models. Our control variables and the time-varying country and time-invariant bilateral fixed effects explain about $93 \%$ of the variation is bilateral import shares per good. Given our identification strategy, the estimated coefficient of the SPS dummy is to be interpreted as the average change in annual bilateral imports caused by 
the introduction of at least one restrictive measure by the importing country. ${ }^{12}$ In column (1) and (2), the SPS $i j t$ coefficient is equal to -0.013 . The coefficient estimates are statistically significant at the $1 \%$ level. As shown in the lower part of Table 3.2, this corresponds to an estimate of -0.187 at the mean value of import shares. This implies that on average, aggregate agricultural exports from a country raising a specific trade concern fall by $17 \%$ (i.e., $[\exp (-0.187)-1] \times 100)$ if at least one concern is raised against an SPS measure implemented by the importer. This estimate is very close to the $14 \%$ estimated in Disdier et al. (2008) for OECD imports.

What is new in our contribution is that we are able to show that these average effects mask a substantial amount of heterogeneity across exporting countries. This is the inherent advantage that our analysis has over existing works. The lower part of Table 3.2 shows that the trade effect at the 30th percentile of import shares is $99 \%$. This reduces to $70 \%$ at the 50 th percentile

TABLE 3.2: The effect of standards on agricultural trade: translog gravity model

\begin{tabular}{lcc}
\hline Dependent variable & $\frac{x_{i j t} / y_{j t}}{n_{i t}}>0$ & $\frac{x_{i j t} / y_{j t}}{n_{i t}}$ \\
\cline { 2 - 3 } & $(1)$ & $(2)$ \\
\hline SPS $_{i j t}$ & $-0.013^{* * *}$ & $-0.013^{* * *}$ \\
Log $\left(1+\right.$ Tariff $\left._{i j t}\right)$ & $(0.002)$ & $(0.002)$ \\
& $-0.001^{*}$ & $-0.001^{*}$ \\
RTA $_{i j t}$ & $(0.001)$ & $(0.000)$ \\
& 0.003 & 0.003 \\
SPS estimates & $(0.003)$ & $(0.003)$ \\
Mean & & -0.183 \\
30th percentile & -0.187 & -5.060 \\
50th percentile & -5.167 & -1.170 \\
90th percentile & -1.194 & -0.073 \\
\hline$R^{2}$ & -0.075 & 0.927 \\
Observations & 0.930 & 87,120 \\
\hline Non
\end{tabular}

Notes: Robust country-pair-product clustered standard errors in parentheses. ${ }^{* * *},{ }^{* *},{ }^{*}$ denote significance at $1 \%$, $5 \%$ and $10 \%$ respectively. Importer-time, exporter-time, and importer-exporter fixed effects included in all regressions. Intercepts included but not reported. Columns 2 excludes zero trade shares. The dependent variable are import shares measured as the aggregate of agricultural trade, i.e., HS01 - HS24). Except for tariffs all explanatory variables enter the regression as dummy variables.

\footnotetext{
${ }^{12}$ The percentage change in trade flows from a change in a dummy variable is computed as $\exp (\hat{\beta}-1) \times 100$.
} 
and further down to $7 \%$ at the 90 th percentile. ${ }^{13}$ This implies that for countries trading large volumes, standards have limited negative effects. This is a conclusion that is overlooked in the existing literature since the estimated CES gravity models yield estimates that are constant. To see the essence of our contribution, we plot in Figure 3.2 the estimated trade cost elasticities reported in columns (2) along with their $95 \%$ confidence intervals across percentiles of the trade share values. We observe that the estimated effects are heterogeneous across import shares. At the 90th percentile of predicted import shares, where imports are large, the standard-trade effect is relatively small at near 0 . However, as we move to lower percentiles (where import shares are small), the estimated trade effects become larger. For comparison, we also plot the constant elasticity from the traditional log-linear CES OLS gravity model which yields an average effect of -0.313 in the same graph (see Table A3.2 in the Appendix). ${ }^{14}$

An added advantage of the translog modelling framework is that it enables us to retrieve country-pair specific estimates of a trade policy shock. For example, consider the case of STCs raised or supported against SPS measures maintained by the EU15 in 2017 — the last year of our panel. The EU has a reputation for setting overly stringent standards and is the leading country maintaining the most restrictive SPS trade measures for which concerns are raised. Table 3.3 shows that the magnitude of the trade effect increases as the import shares in the EU15 decreases. Underlying this significant heterogeneity in the estimated trade effects is the import shares of the exporting countries in the gross imports of the importing country. For brevity, we leave the full bilateral trade effects for each of the 20 years to the Appendix (see Table A3.6).

Overall, the results are in-line with our expectations. Consistent with much of the existing literature, we confirm that stricter importing country standards are indeed trade-restrictive (Disdier et al., 2008; Fernandes et al., 2019; Curzi et al., 2018; Kinzius et al., 2018). That is to mean that the stricter an importing country standard, the less exports is observed to that country. In line with Melitz (2003) and Helpman et al. (2008) type models, a stringent

\footnotetext{
${ }^{13}$ The $\mathrm{SPS}_{i j t}$ estimates at the 10th and 20th percentiles are extremely large. The reason is that the translog imposes a hyperbolic functional form on the way our elasticities of interested are computed (Chen and Novy, 2018). Because import shares at low percentiles are very close to zero, the implied elasticities tend to become very large.

${ }^{14}$ Note that direct comparison of the estimates is not feasible, for one, because the dependent variable in the translog model denotes shares whereas the standard gravity model denotes volumes as the dependent variable. For another, the estimate obtained from the translog model is not an elasticity as it is for the standard gravity framework.
} 
FIGURE 3.2: Trade cost elasticities plotted against import shares

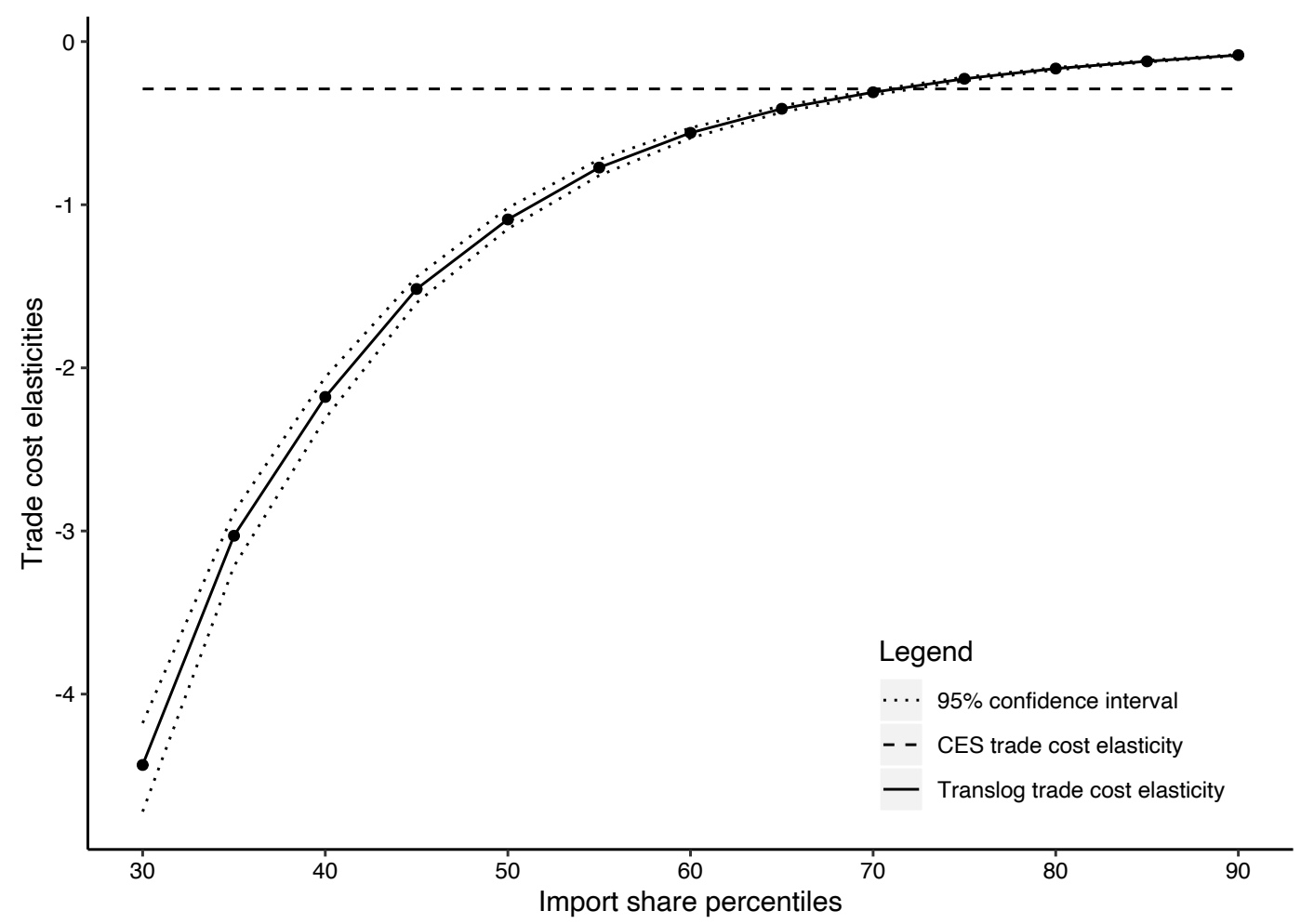

importing country standard induces a selection effect by raising fixed and variable trade costs that discriminates against non-compliant producers. But consistent with findings at the firm-level (Fontagné et al., 2016; Fernandes et al., 2019; Curzi et al., 2020) we see that the negative effects are reducing with importer size which we measure as import shares. At the country-level, our findings are in line with Anders and Caswell (2009) who focus on the US as an importer and Ehrich et al. (2017) who focus on maximum residue limits. But there are also some notable differences. Anders and Caswell (2009) find that for HACCP standards neither the "standards as barriers/catalyst" hypothesis fits developing countries as a whole. Among developing countries increased standards act as a catalyst for larger, more established exporting countries and a barrier for smaller exporters. Ehrich et al. (2017) also report positive effects at high deciles of the trade flow distribution and negative effects at lower deciles. We, on the other hand, find that for SPS STCs, the standards-as-barriers effect prevails for all countries - developed and developing - and trade volumes, but with magnitudes that are smaller for more established trading partners who have high import shares regardless of 
TABLE 3.3: Country-pair specific estimates of the effects of EU-15 standards in agricultural trade in 2017

\begin{tabular}{lllcl}
\hline Exporting country & $\begin{array}{l}\text { Trade value } \\
\text { (m USD) }\end{array}$ & $\begin{array}{l}\text { Import share } \\
\text { (in \%) }\end{array}$ & Trade cost elasticity & Income status \\
\hline Fiji & 107 & 0.027 & -11.950 & Low \\
Cuba & 368 & 0.091 & -2.896 & Low \\
Tanzania & 413 & 0.103 & -3.090 & Low \\
Senegal & 459 & 0.114 & -2.781 & Low \\
Uruguay & 663 & 0.164 & -1.927 & High \\
Israel & 1033 & 0.256 & -1.236 & High \\
Egypt & 1080 & 0.268 & -1.183 & Low \\
Phillipines & 1416 & 0.351 & -0.902 & Low \\
Russia & 1622 & 0.403 & -0.787 & High \\
Colombia & 2236 & 0.555 & -0.571 & Low \\
Australia & 2440 & 0.606 & -0.524 & High \\
Peru & 2767 & 0.687 & -0.462 & Low \\
Thailand & 3050 & 0.757 & -0.419 & Low \\
Ecuador & 3115 & 0.773 & -0.410 & Low \\
South Africa & 3752 & 0.931 & -0.340 & Low \\
Côte d'Ivoire & 4215 & 1.046 & -0.303 & Low \\
India & 4755 & 1.180 & -0.269 & Low \\
Indonesia & 5198 & 1.290 & -0.246 & Low \\
Argentina & 5881 & 1.460 & -0.217 & Low \\
China & 7467 & 1.853 & -0.171 & Low \\
Brazil & 12600 & 3.126 & -0.101 & Low \\
USA & 12800 & 3.184 & -0.100 & High \\
\hline
\end{tabular}

Notes: Estimates are based on exporting countries that raised or supported a Specific Trade Concern maintained against the EU-15 in 2017. Also note that import shares do not add up to $100 \%$ as shares are given by the exporter country's market share per good in the importing country. Here we kept the importer (EU-15) fixed and show the variation in shares across export partners.

their development status. ${ }^{15}$ Another implication of our results is that while the standards effect on trade is mainly discussed from a North-South perspective - with countries in the South finding it more difficult to comply - these generalisations may not necessarily be the whole story. Even in developing countries some producers will make the effort to meet importingcountry specific standards if those firms command a relatively large market share in that importing country. For example, in Table 2 we see that developing countries such as Indonesia, Côte d'Ivoire, Ecuador, Thailand and Peru

\footnotetext{
${ }^{15}$ The fact that our conclusions on the standards-trade effect differs from Anders and Caswell (2009) and Ehrich et al. (2017) is not surprising and may just offer insights into some underlying mechanisms driving our results. These two studies focus on specific standards (HACCP and maximum residue limits) that may not necessarily be trade restrictive. Even if their stringency levels change intermittently, producers may suffer in the short term until they adjust completely to the standard and can then increase trade volumes. This is not necessarily the case for the broad SPS measures we focus on, and especially regarding the fact that we select out overly stringent measures.
} 
are relatively less affected by stringent standards in the EU-15 than developed countries such as Australia, Russia, Israel and Uruguay.

So why may standards affect smaller trading partners more than larger ones? Standards impose both fixed costs, (e.g., investing in new production techniques or adjustments to existing ones) and variable trade costs (e.g., costly inputs, recurrent costs of quality control, and product testing) for producers. The fixed cost component of a standard will affect mainly the extensive margin as increased production costs induce market exit for noncompliant firms, while the effect on the intensive margins is a priori undetermined. Standards increase production costs and may reduce export volumes but the extra costs may be compensated by increased market access due to quality upgrading and/or more consumer information. It is intuitive to assume that for more established trading relationships, exporters would have already invested in meeting the fixed costs imposed by the importer. For smaller trading partners the fixed cost component is very high and thus affects to a large degree their trade flows to the country maintaining the standard. It is also possible that bilateral relationships with higher import shares will imply that the particular exporter involved in that trading relationship has a lot of importer-specific experience. This is consistent with Grant et al. (2015) who show that the negative effects of SPS standards diminishes as U.S. exporters accumulate treatment experience. The underlying mechanism is consistent with a "learning-by-doing" framework whereby bilateral trading relationships with higher trade volumes are are able to treat shipments more efficiently as their cumulative experience grows (Grant et al., 2015).

Regarding the other control variables, bilateral tariffs and regional trade agreements have the expected negative and positive effects on bilateral trade flows, respectively. By nature tariffs and SPS measures cannot be compared directly. Whilst tariffs are by nature trade reducing, NTMs can be measures for market creation. So, even though our results show that tariffs and standards have qualitatively similar effects on trade flows, these two trade policy instruments may affect market structure differently. For instance, standards unlike tariffs affect both domestic producers and foreign exporting firms. As a result standards displace smaller firms-both domestic and foreignin favour of larger firms (Asprilla et al., 2019). The estimated coefficient for the RTA dummy is positive. This is consistent with the theoretical prediction that trade preferences enhance trade flows. However, the estimated effects are not statistically significant. This is because the extensive fixed effects in our model specifications absorb most of the variations in the RTA variable. 
Not controlling for bilateral fixed effects yields a statistically significant RTA effect. It is possible that these other control variables also affect agricultural trade in a heterogeneous fashion. However, these go beyond the scope of our paper. We refer the interested reader to Novy (2013) for the tariff case and Chen and Novy (2018) for trade agreements.

\subsection{Sensitivity Analysis}

\subsubsection{CES gravity model with heterogeneous SPS effects on trade}

One concern with our findings is whether the results are model driven. To refute this argument we estimate a CES gravity model with the exporter's market share per good in importing country $j$ as the dependent variable using PPML and incorporate heterogeneous effects of SPS measures. ${ }^{16}$ Our baseline regression in the translog framework is estimated using OLS. This is because the dependent variables are in levels and so our regressions retain zero trade shares. This is not the case for the CES model which will require that we log transform the dependent variable. As a result, in this part of the analysis we employ the non-linear Poisson-pseudo maximum likelihood (PPML) estimator (Santos Silva and Tenreyro, 2006) which has become the gold standard in the CES gravity model. This estimator's loglinear objective function allows us to specify our estimation equation in its multiplicative form without log-transforming the dependent variable as follows:

$$
\frac{x_{i j t} / y_{j t}}{n_{i t}}=\exp \left[-\beta^{\prime} \mathbf{w}_{i j t}+\psi_{i t}+\lambda_{j t}+\alpha_{i j}\right]+e_{i j t}
$$

For that purpose of accounting for heterogeneous standards-trade effects, we include the interaction between our variable of interest and quartiles of predicted market shares per good into equation (4.5). If the trade effect of standards falls with higher exporter's market share as predicted by the translog gravity model, we would expect the trade effect to be declining but pronounced for the lowest quartile of predicted market shares. We use predictions according to Novy (2013) to circumvent simultaneity between the

\footnotetext{
${ }^{16}$ Unlike the translog gravity model, the CES gravity equation estimated using PPML is $\log$-linear in trade costs. Since variations of the extensive margin $n_{i t}$ and the importer size term (i.e., total imports or GDP) $y_{j t}$ of the dependent variable are absorbed by the exporteryear and importer-year fixed effects the remaining variation in market shares is derived from trade volumes between $i$ and $j$. Therefore we effectively regress trade volumes in logs.
} 
TABLE 3.4: The heterogeneous effect of standards on agricultural trade: standard CES gravity model

\begin{tabular}{lcc}
\hline & $(1)$ & $(2)$ \\
\hline SPS $_{i j t}$ & $-0.051^{* *}$ & \\
SPS $_{i j t} \times$ predicted shares (First interval) & $(0.026)$ & $-3.470^{* * *}$ \\
SPS $_{i j t} \times$ predicted shares (Second interval) & & $(0.145)$ \\
SPS $_{i j t} \times$ predicted shares (Third interval) & $-1.174^{* * *}$ \\
SPS $_{i j t} \times$ predicted shares (Fourth interval) & & $(0.066)$ \\
& & $-0.471^{* * *}$ \\
Log $(1+$ Tariff \\
& & $(0.045)$ \\
RTA $\left._{i j t}\right)$ & -0.021 & -0.028 \\
& $(0.016)$ & $(0.026)$ \\
Observations & 0.008 & $(0.015)$ \\
\end{tabular}

Notes: Robust country-pair-product clustered standard errors in parentheses. ${ }^{* * *},{ }^{* *},{ }^{*}$ denote significance at $1 \%, 5 \%$ and $10 \%$ respectively. Importer-time, exporter-time, and importer-exporter fixed effects included in all regressions. Intercepts included but not reported. The dependent variables are observed trade values. All models are estimated using PPML. The dummy for predicted shares is omitted due to perfect collinearity with the importer-time fixed effects.

dependent variable and the standards effects. The estimation equation for quartile regressions in which the standards-trade effect is estimated for each interval of market shares reads as

$\frac{x_{i j t} / y_{j t}}{n_{i t}}=\exp \left[-\gamma \mathbf{r} \beta^{\prime} \mathbf{w}_{i j t}+\delta_{i n t} S P S_{i j t} \times D_{i n t}+\psi_{i t}+\lambda_{j t}+\alpha_{i j}+D_{i n t}\right]+e_{i j t}$.

Quartile dummies $D_{\text {int }}$ enter the estimation as indicators interacted with $S P S_{i j t}$ to obtain the corresponding heterogeneous coefficients $\delta_{\text {int }}$ across quartiles and also as quartile fixed effects. The first term on the right-hand side includes a $(1 \times 3)$ vector $\mathbf{r}$ which selects out bilateral tariffs and regional trade agreements from the initial trade cost vector $w_{i j t}$.

The results are presented in Table 3.4. In column (1) we estimate the homogeneous effect of standards on agricultural trade. The coefficient of -0.051 implies that an increase or introduction of standards are associated with a decrease in bilateral trade of 5 percent on average. Because the CES utility function is homothetic, the presence of a specific trade concern will yield a proportional decrease in trade, all else being equal. Interestingly, the 
standard effect is larger than the tariff and RTA effect in terms of its magnitude with the estimates for latter two being even insignificant. In column (2) we show the estimated standards effects for each quartile of predicted market share per good. The first quartile refers to the interval with the lowest import shares. As expected, the standards coefficient is largest $(-3.470)$ in magnitude for the first quartile and continues to fall with higher quartiles. Consistent with the predictions from the translog gravity framework, the estimated negative trade effect of stricter importing country food standards varies depending on how intensively two countries trade.

\subsubsection{Further robustness checks}

In this section we conduct further checks to confirm the robustness of our findings. Our baseline models use contemporaneous values of our SPS variables. However, it is also possible that NTMs are implemented in reaction to a sudden increase in imports from a particular exporter. STCs may also target new SPS measures which are to come into force in the near future. As a consequence, Crivelli and Gröschl (2016) and Fontagné et al. (2015) argue that a contemporary SPS measure inadequately captures the "true" variation and use the first lag of the variable on SPS to circumvent the attenuation bias. As a first check of the robustness of our baseline findings, we use the one year lag of SPS. Doing this further bolster our estimations against the potential problem of reverse causality between import shares and SPS measures. The results are presented in Table 3.5. Our main findings remain qualitatively the same and the magnitudes differ only slightly. In column (1), the lagged SPS coefficient, SPS ijt-1 $_{1}$ is equal to -0.012. As shown in the lower part of the table, this corresponds to an estimate of -0.165 at the mean value of import shares. This implies that on average, aggregate agricultural imports from a country raising a specific trade concern fall by $15 \%$ if at least one SPS is implemented by the importer. This implies a 2 percentage point decrease from using the contemporaneous SPS measure in Table 3.2. If there would be an attenuation bias then our estimate for $\mathrm{SPS}_{i j t-1}$ should be in fact larger in terms of magnitude.

Our baseline sample includes only bilateral pairs that raise or maintain an SPS STC at least once over the length of the panel. SPS measures are unilateral - i.e., if an importer introducing a standard it affects all other

exporters - but STCs are bilateral. As argued by Beverelli et al. (2019), an exporter may not complain about a measure simply because the importer's 
TABLE 3.5: Robustness check - translog gravity model: lagged SPS values

\begin{tabular}{lcc}
\hline \multirow{2}{*}{ Dependent variable } & $\frac{x_{i j t} / y_{j t}}{n_{i t}}>0$ & $\frac{x_{i j t} / y_{j t}}{n_{i t}}$ \\
\cline { 2 - 3 } & $(1)$ & $(2)$ \\
\hline SPS $_{i j t-1}$ & $-0.012^{* * *}$ & $-0.011^{* * *}$ \\
$\log \left(1+\right.$ Tariff $\left._{i j t}\right)$ & $(0.002)$ & $(0.002)$ \\
& $-0.001^{*}$ & -0.001 \\
RTA $_{i j t}$ & $(0.001)$ & $(0.000)$ \\
& 0.003 & 0.003 \\
& $(0.003)$ & $(0.003)$ \\
\hline
\end{tabular}

SPS estimates

Mean

$-0.165-0.159$

30th percentile

$-4.563-4.385$

50th percentile

$-1.055$

$-1.014$

90th percentile

$-0.066$

$-0.063$

Observations

72,859

82,764

Notes: Robust country-pair-product clustered standard errors in parentheses. ${ }^{* * *}, * *, *$ denote significance at $1 \%$, $5 \%$ and $10 \%$ respectively. Importer-time, exporter-time, and importer-exporter fixed effects included in all regressions. Intercepts included but not reported. The dependent variables are import shares. Columns 2 excludes zero trade shares.

market is irrelevant. In this case we would not observe an STC, although the importer may have a trade restrictive measure in place. As a result, we expand our data sample to include trade between all exporting countries and all importing countries regardless of whether they raised a concern over the length of our panel. As a result, the sample here is bilateral trade between 159 exporting countries (including the EU 15) and 92 importing countries. The results presented in Table A3.3 of the appendix supports our main findings. The reduced sample is not driving our results.

We have so far captured the presence of an STC as a dichotomous variable. Keeping in mind the limitations of using the counts of STCs present, we test our findings using the counts of cumulative STCs in place in year $t$. Here the interpretation of our SPS variable of interest changes to the average change in imports following the implementation of one additional protectionist policy. Our main conclusions remain unchanged. See Table A3.4 of the appendix. Finally, our translog models control adequately for zeroes. However, to see how robust our specification is to other estimators, we employ the PPML within the translog gravity framework. Our main findings remain the same, but the estimated magnitudes in the PPML are higher in magnitude. 


\subsection{Conclusion}

How standards affect agricultural trade has been a subject of intense scrutiny. The rapid increase in the number of published studies assessing the standardstrade nexus - from about 14 in the year 2000 to about 140 studies in 2017 (Santeramo and Lamonaca, 2019) - is a good case in point. A limitation of this strand of literature is that the existing estimates are all from gravity models that impose the limited assumption that the estimated trade effect is a constant. These lead to one-size fits all type of conclusions, which this paper challenges.

In this paper, we provide the first set of empirical evidence on the heterogeneous effects of standards on agricultural trade considering import shares. Consistent with existing research, we confirm that stricter standards are indeed trade restrictive. However, unlike existing works, we show that the estimated trade cost elasticity varies depending on how intensively two countries trade. This means that for countries trading large volumes, standards have only limited negative effects. Thus, standards-related trade costs have heterogeneous trade-reducing effects. Our finding that there is a significant heterogeneity underlying the simple "standards-as-barriers" argument that goes beyond the typical developed-developing country-specific effects - has far-reaching policy implications. This is important from a public policy point of view; for one, working with country-pair specific estimates of a trade policy shock - instead of the usual average effect across country-pairs - will enhance evidence-based policy-making. Even more important is that smaller trading partners will benefit more from further NTM liberalisation or harmonisation of standards.

Our work is not without its limitations. By focusing on SPS measures which cover a broad range of policy instruments we provide general results on the effects of standards in the agricultural sector. However, we do not provide precise estimates on the effects of a specific standard on trade, e.g., maximum residue limits. We also provide results that refer to the general agricultural sector and do not provide product-specific findings. To better understand the mechanisms driving our results, extensions of our analysis should consider specific standards, specific products. Further analysis could also focus on firm level transactions and customs data. Furthermore, our measure of standards measure the prevalence of standards, but not their stringency. This makes it difficult to compare the stringency of standards between countries. Further studies could employ continuous measures of 
relative stringency set on specific products, e.g., maximum residue limits, to compare differences in country-pair specific standards. And finally, extensions of our analysis should consider applications of the translog gravity model at the product-level or using firm-level data. The former will allow us to understand if the observed heterogeneity exist even at the product level. 


\subsection{Appendix}

\section{Deriving the translog gravity model following Novy (2013)}

The translog type expenditure function is defined as:

$$
\ln \left(E_{j}\right)=\ln \left(U_{j}\right)+\alpha_{0 j}+\sum_{m=1}^{N} \alpha_{m} \ln \left(p_{m j}\right)+\frac{1}{2} \sum_{m=1}^{N} \sum_{k=1}^{N} \gamma_{k m} \ln \left(p_{m j} \ln \left(p_{k j}\right)\right.
$$

, where $\mathrm{m}, \mathrm{k}$ indexes the goods. The $\alpha$ parameters depict the preference weights for country $\mathrm{m}$-th goods, and the $\gamma_{m k}$ parameters indicate substitutability between goods $\mathrm{m}$ and $\mathrm{k}$.

Linear homogeneity condition requires

$$
\sum_{m=1}^{N} \alpha_{m}=1, \sum_{k=1}^{N} \gamma_{m k}=0, \gamma_{m k}=\gamma_{k m} \forall m, k=1, \ldots, N
$$

As in Feenstra (2003), all goods enter "symmetrically" into expenditure such that

$$
\alpha_{i}=\frac{1}{N} ; \gamma_{i i}=\gamma \frac{(1-N)}{N} \forall i ; \gamma_{i j}=\frac{\gamma}{N} \forall i \neq j
$$

Applying Shephard's Lemma to the expenditure function yields the import share equation

$$
s_{m j}=\frac{x_{m j}}{y_{j}}=\alpha_{m}+\sum_{k=1}^{N} \gamma_{k m} \ln \left(p_{k j}\right)
$$

, where $s_{m j}$ is the share of country m's goods in country j's gdp $\left(y_{j}\right)$ and $x_{m j}$ is the nominal trade value of country j's imports of good $\mathrm{m}$.

The sum of expenditure shares across all goods originating from country $i$ then equals

$$
\sum_{m=N_{i-1}+1}^{N_{i}} s_{m j}=\frac{x_{i j}}{y_{j}}=\sum_{m=N_{i-1}+1}^{N_{i}}\left(\alpha_{m}+\sum_{k=1}^{N} \gamma_{k m} \ln \left(p_{k j}\right)\right)
$$

The destination price $p_{m j}=\tau_{m j} p_{m}$ is the price of good $\mathrm{m}$ in importing country $\mathbf{j}$, where $p_{m}$ denotes the net price for good $\mathrm{m}$ and $\tau_{m j}>1, \forall m \neq j$, otherwise $\tau_{j j}=1$, reflects the icerberg type of costs of trading.

Imposing market clearance and substituting yields 


$$
y_{i}=\sum_{j=1}^{J} x_{i j}=\sum_{j=1}^{J} y_{j} \sum_{m=N_{i-1}+1}^{N_{i}}\left(\alpha_{m}+\sum_{k=1}^{N} \gamma_{k m} \ln \left(\tau_{k j} p_{k}\right)\right)
$$

Define aggregate global expenditure on agricultural goods as $y_{\text {global }}=$ $\sum_{j=1}^{J} y_{j}$ and solving for net prices yields

$$
\sum_{m=N_{i-1}+1}^{N_{i}} \sum_{k=1}^{N} \gamma_{m k} \ln \left(p_{k}\right)=\frac{y_{i}}{y_{\text {global }}}-\sum_{s=1}^{J} \frac{y_{s}}{y_{\text {global }}} \sum_{m=N_{i-1}+1}^{N_{i}}\left(\alpha_{m}+\sum_{k=1}^{N} \gamma_{k m} \ln \left(\tau_{k s}\right)\right)
$$

Following Novy (2013) the first summation index on the right-hand side is changed from $\mathrm{j}$ to $\mathrm{s}$ to consider multilateral resistance. Net prices are substituted back into expenditure shares yielding

$$
\begin{gathered}
\frac{x_{i j}}{y_{j}}=\sum_{m=N_{i-1}+1}^{N_{i}}\left(\alpha_{m}+\sum_{k=1}^{N}\left(\gamma_{m k} \ln \left(\tau_{k j}\right)\right)+\frac{y_{i}}{y_{\text {global }}}-\sum_{s=1}^{J} \frac{y_{s}}{y_{\text {global }}} \sum_{m=N_{i-1}+1}^{N_{i}}\left(\alpha_{m}+\sum_{k=1}^{N} \gamma_{k m} \ln \left(\tau_{k s}\right)\right)\right. \\
\frac{x_{i j}}{y_{j}}=\frac{y_{i}}{y_{\text {global }}}+\underbrace{\sum_{s=1}^{J} \frac{y_{s}}{y_{\text {global }}}}_{=1} \sum_{m=N_{i-1}}^{N_{i}} \sum_{k=1}^{N} \gamma_{m k} \ln \left(\tau_{k j}\right)-\sum_{s=1}^{J} \frac{y_{s}}{y_{g l o b a l}} \sum_{m=N_{i-1}+1}^{N_{i}} \sum_{k=1}^{N} \gamma_{k m} \ln \left(\tau_{k s}\right) \\
\frac{x_{i j}}{y_{j}}=\frac{y_{i}}{y_{g l o b a l}}+\sum_{s=1}^{J} \frac{y_{s}}{y_{g l o b a l}} \sum_{m=N_{i-1}}^{N_{i}} \sum_{k=1}^{N}\left(\gamma_{k m} \ln \left(\tau_{k j}\right)-\gamma_{k m} \ln \left(\tau_{k s}\right)\right) \\
\frac{x_{i j}}{y_{j}}=\frac{y_{i}}{y_{\text {global }}}+\sum_{s=1}^{J} \frac{y_{s}}{y_{g l o b a l}} \sum_{m=N_{i-1}+1}^{N_{i}} \sum_{k=1}^{N} \gamma_{k m} \ln \left(\frac{\tau_{k j}}{\tau_{k s}}\right) .
\end{gathered}
$$

Taking the $\mathrm{m}$-th good out of the running index

$$
\frac{x_{i j}}{y_{j}}=\frac{y_{i}}{y_{\text {global }}}+\sum_{s=1}^{J} \frac{y_{s}}{y_{\text {global }}} \sum_{m=N_{i-1}+1}^{N_{i}} \sum_{k=1, k \neq m}^{N}\left(\gamma_{k m} \ln \left(\frac{\tau_{k j}}{\tau_{k s}}\right)+\gamma_{m m} \ln \left(\frac{\tau_{m j}}{\tau_{m s}}\right)\right)
$$

and exploiting symmetry renders 
$\frac{x_{i j}}{y_{j}}=\frac{y_{i}}{y_{\text {global }}}+\sum_{s=1}^{J} \frac{y_{s}}{y_{\text {global }}} \sum_{m=N_{i-1}+1}^{N_{i}} \sum_{k=1, k \neq m}^{N}\left(\frac{\gamma}{N} \ln \left(\frac{\tau_{k j}}{\tau_{k s}}\right)+\gamma \frac{(1-N)}{N} \ln \left(\frac{\tau_{m j}}{\tau_{m s}}\right)\right)$.

Multiplying out the last term on the RHS and letting the running index cover the $\mathrm{m}$-th good again leads to

$$
\frac{x_{i j}}{y_{j}}=\frac{y_{i}}{y_{\text {global }}}+\sum_{s=1}^{J} \frac{y_{s}}{y_{\text {global }}} \sum_{m=N_{i-1}+1}^{N_{i}}\left(\sum_{k=1}^{N} \frac{\gamma}{N} \ln \left(\frac{\tau_{k j}}{\tau_{k s}}\right)-\gamma \ln \left(\frac{\tau_{m j}}{\tau_{m s}}\right)\right) .
$$

? then uses the logged geometric mean of trade costs in country $j$ as

$$
\begin{gathered}
T_{j} \equiv \prod_{k=1}^{N} t_{k j} \\
\ln \left(T_{j}\right)=\frac{1}{N} \sum_{k=1}^{N} \ln \left(\tau_{k j}\right)
\end{gathered}
$$

and assumes that trade costs to country $j$ are the same for all goods from country of origin $i$, i.e. $t_{m j}=t_{i j} \forall m \in\left[N_{i-1}, N_{i}\right]$.

$$
\begin{aligned}
& \frac{x_{i j}}{y_{j}}=\frac{y_{i}}{y_{\text {global }}}+\sum_{s=1}^{J} \frac{y_{s}}{y_{\text {global }}} \underbrace{\sum_{m=N_{i-1}+1}^{N_{i}}}_{n_{i}}\left(\gamma \ln \left(\frac{T_{j}}{T_{s}}\right)-\gamma \ln \left(\frac{\tau_{i j}}{\tau_{i s}}\right)\right) \\
& \frac{x_{i j}}{y_{j}}=\frac{y_{i}}{y_{\text {global }}}+\sum_{s=1}^{J} \frac{y_{s}}{y_{\text {global }}} n_{i}\left(\gamma \ln \left(T_{j}\right)-\gamma \ln \left(T_{s}\right)-\gamma \ln \left(\tau_{i j}\right)+\gamma \ln \left(\tau_{i s}\right)\right) \\
& \frac{x_{i j}}{y_{j}}=\frac{y_{i}}{y_{\text {global }}}+\underbrace{\sum_{s=1}^{J} \frac{y_{s}}{y_{\text {global }}}}_{=1} n_{i} \gamma \ln \left(T_{j}\right)-\sum_{s=1}^{J} \frac{y_{s}}{y_{\text {global }}} n_{i} \gamma \ln \left(T_{s}\right) \\
& -\underbrace{\sum_{s=1}^{J} \frac{y_{s}}{y_{\text {global }}}}_{=1} n_{i} \gamma \ln \left(\tau_{i j}\right)+\sum_{s=1}^{J} \frac{y_{s}}{y_{\text {global }}} n_{i} \gamma \ln \left(\tau_{i s}\right)
\end{aligned}
$$


$\frac{x_{i j}}{y_{j}}=\frac{y_{i}}{y_{\text {global }}}+n_{i} \gamma \ln \left(T_{j}\right)-\sum_{s=1}^{J} \frac{y_{s}}{y_{\text {global }}} n_{i} \gamma \ln \left(T_{s}\right)-n_{i} \gamma \ln \left(\tau_{i j}\right)+\sum_{s=1}^{J} \frac{y_{s}}{y_{\text {global }}} n_{i} \gamma \ln \left(\tau_{i s}\right)$

$$
\frac{x_{i j}}{y_{j}}=\frac{y_{i}}{y_{\text {global }}}+n_{i} \gamma \ln \left(T_{j}\right)-n_{i} \gamma \ln \left(\tau_{i j}\right)+\sum_{s=1}^{J} \frac{y_{s}}{y_{\text {global }}} n_{i} \gamma \ln \left(\frac{\tau_{i s}}{T_{s}}\right)
$$


TABLE A3.1: List of importing and exporting countries

Importers

Albania, Argentina, Armenia, Australia, Bahrain, Barbados, Bolivia, Brazil, Bulgaria, Canada, Chile, China, Colombia, Costa Rica, Croatia, Cuba, Cyprus, Czech Republic, Dominican Republic, Egypt, El Salvador, Estonia, EU-15, Gabon, Germany, Guatemala, Honduras, Hungary, Iceland, India, Indonesia, Israel, Japan, Jordan, South Korea, Kuwait, Latvia, Lithuania, Malaysia, Malta, Mexico, New Zealand, Nigeria, Oman, Panama, Philippines, Poland, Qatar, Russian Federation, Saudi Arabia, Senegal, Singapore, Slovakia, Slovenia, South Africa, Suriname, Switzerland-Liechtenstein, Taiwan, Thailand, Trinidad and Tobago Turkey, Ukraine, United Arab Emirates, United States of America, Uruguay, Venezuela, Viet Nam

Exporters

Argentina, Australia, Austria, Belgium-Luxembourg, Brazil, Bulgaria, Canada, Chile, China, Colombia, Costa Rica, Croatia, Cuba, Cyprus, Czech Republic, Côte d'Ivoire, Denmark, Ecuador, Egypt, Estonia, Fiji, Finland, France, Germany, Greece, Guatemala, Hungary, India, Indonesia, Ireland, Israel, Italy, Latvia, Lithuania, Malta, Mexico, Netherlands, New Zealand, Nicaragua, Nigeria, Norway, Pakistan, Papua New Guinea, Peru, Philippines, Poland, Portugal, Russian Federation, Saint Vincent and the Grenadines, Senegal, Slovakia, Slovenia, South Africa, Spain, Sri Lanka, Sweden, Switzerland-Liechtenstein, Taiwan, Tanzania, Thailand, Ukraine, United Kingdom, United States of America, Uruguay, Venezuela, Viet Nam 
TABLE A3.2: The effect of standards on agricultural trade: standard gravity model using OLS

Dependent variable

$\ln X_{i j t}$

$(1)$

\begin{tabular}{lc}
\hline SPS $_{i j t}$ & $-0.313^{* * *}$ \\
& $(0.033)$ \\
Log Tariff & \\
& \\
RTA $_{i j t}$ & -0.004 \\
& $(0.014)$ \\
Observations & -0.020 \\
\hline
\end{tabular}

Notes: Robust country-pair-product clustered standard errors in parentheses. ${ }^{* * *}, * *, *$ denote significance at $1 \%, 5 \%$ and $10 \%$ respectively. Importer-product-time, exporter-product-time, and importer-exporter fixed effects included in all regressions. Intercepts included but not reported. The dependent variables in Columns (1) and (2) are dummies defined for the probability of trading and exit respectively and are estimated using a linear probability model.

TABLE A3.3: Translog gravity model: Bilateral trade between all exporting and importing countries

\begin{tabular}{lcc}
\hline Dependent variable & $\left(x_{i j t} / y_{j t}\right)>0$ & $x_{i j t} / y_{j t}$ \\
\cline { 2 - 3 } & $(1)$ & $(2)$ \\
\hline SPS $_{i j t}$ & $-0.011^{* * *}$ & $-0.010^{* * *}$ \\
& $(0.002)$ & $(0.002)$ \\
Log $\left(1+\right.$ Tariff $\left._{i j t}\right)$ & $-0.001^{* * *}$ & $-0.000^{* * *}$ \\
& $(0.000)$ & $(0.000)$ \\
RTA $_{i j t}$ & 0.001 & 0.001 \\
& $(0.002)$ & $(0.001)$ \\
\hline Importer-time FE & Yes & Yes \\
Exporter-time FE & Yes & Yes \\
Exporter-Importer FE & Yes & Yes \\
Observations & 177,426 & 292,560 \\
\hline
\end{tabular}

Notes: Robust country-pair-product clustered standard errors in parentheses. ${ }^{* * *}, * *, *$ denote significance at $1 \%, 5 \%$ and $10 \%$ respectively. Importer-time, exporter-time, and importer-exporter fixed effects included in all regressions. The dependent variables are import shares. Columns 2 excludes zero trade shares. 
TABLE A3.4: Translog gravity model: count of specific trade concerns

Dependent variable

$$
\underline{\left(x_{i j t} / y_{j t}\right)>0}
$$

$x_{i j t} / y_{j t}$

(1)

\begin{tabular}{lcc}
\hline Log SPS & $-0.004^{* * *}$ & $-0.004^{* * *}$ \\
& $(0.001)$ & $(0.001)$ \\
$\log \left(1+\right.$ Tariff $\left._{i j t}\right)$ & $-0.001^{* *}$ & $-0.001^{*}$ \\
& $(0.001)$ & $(0.000)$ \\
RTA $_{i j t}$ & 0.003 & 0.003 \\
& $(0.003)$ & $(0.003)$ \\
\hline Importer-time FE & Yes & Yes \\
Exporter-time FE & Yes & Yes \\
Exporter-Importer FE & Yes & Yes \\
Observations & 76,219 & 87,120 \\
\hline
\end{tabular}

Notes: Robust country-pair-product clustered standard errors in parentheses. $* * * * * * *$ denote significance at $1 \%, 5 \%$ and $10 \%$ respectively. Importer-time, exporter-time, and importer-exporter fixed effects included in all regressions. The dependent variables are import shares. Columns 2 excludes zero trade shares. 
TABLE A3.5: The effect of standards on agricultural trade: translog gravity model using PPML

Dependent variable $\quad \frac{\frac{x_{i j t} / y_{j t}}{n_{i t}}>0}{}$

(1)

$\frac{x_{i j t} / y_{j t}}{n_{i t}}$

$(2)$

\begin{tabular}{lcc}
\hline SPS $_{i j t}$ & $-0.172^{* * *}$ & $-0.183^{* * *}$ \\
& $(0.034)$ & $(0.034)$ \\
Log $\left(1+\right.$ Tariff $\left._{i j t}\right)$ & $-0.058^{* * *}$ & $-0.066^{* * *}$ \\
& $(0.017)$ & $(0.017)$ \\
RTA $_{i j t}$ & 0.044 & 0.043 \\
& $(0.036)$ & $(0.036)$ \\
\hline SPS estimates & & -2.540 \\
Mean & -2.382 & -70.213 \\
30th percentile & -65.836 & -16.236 \\
50th percentile & 15.224 & -1.016 \\
90th percentile & -0.952 & Yes \\
\hline Importer-time FE & Yes & Yes \\
Exporter-time FE & Yes & Yes \\
Exporter-Importer FE & Yes & 85,200 \\
Observations & 76,219 &
\end{tabular}

Notes: Robust country-pair-product clustered standard errors in parentheses. ${ }^{* * * * *}, *$ denote significance at $1 \%$, $5 \%$ and $10 \%$ respectively. Intercepts included but not reported. Columns 2 excludes zero trade shares. The dependent variable are import shares measured as the aggregate of agricultural trade, i.e., HS01 - HS24). Except for tariffs all explanatory variables enter the regression as dummy variables. 


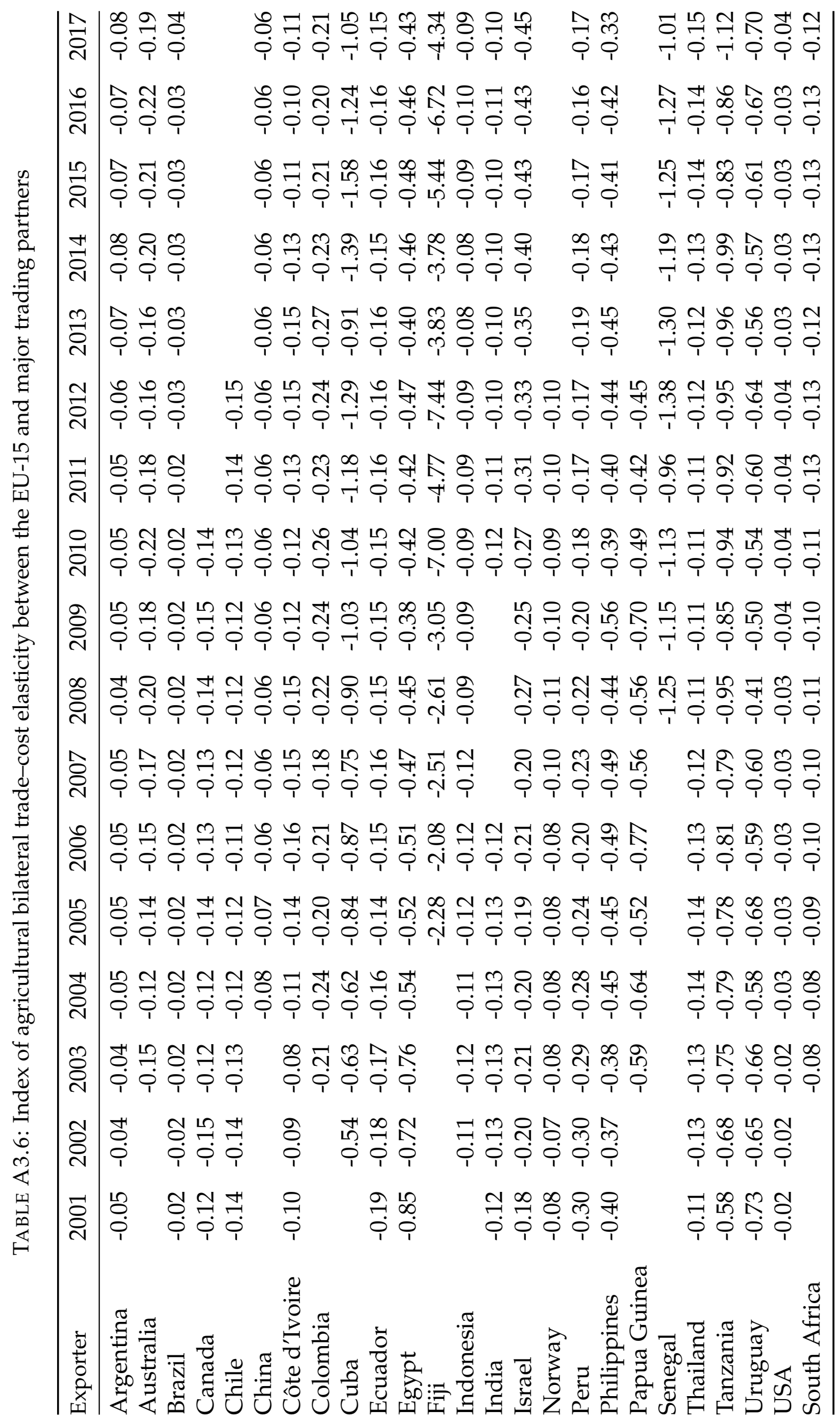




\section{Bibliography}

Ackerberg, D. A., Caves, K. and Frazer, G. (2015), 'Identification properties of recent production function estimators', Econometrica 83(6), 2411-2451.

Agnosteva, D. E., Anderson, J. E. and Yotov, Y. V. (2019), 'Intra-national trade costs: Assaying regional frictions', European Economic Review 112, 32-50.

Ahmadzai, H. (2017), Crop diversification and technical efficiency in afghanistan: Stochastic frontier analysis, Technical report, CREDIT Research Paper.

Aigner, D., Lovell, C. K. and Schmidt, P. (1977), 'Formulation and estimation of stochastic frontier production function models', Journal of econometrics 6(1), 21-37.

Amsler, C., Schmidt, P. and Tsay, W.-J. (2019), 'Evaluating the cdf of the distribution of the stochastic frontier composed error', Journal of Productivity Analysis 52(1-3), 29-35.

Anders, S. M. and Caswell, J. A. (2009), 'Standards as barriers versus standards as catalysts: assessing the impact of HACCP implementation on US seafood imports', American Journal of Agricultural Economics 91(2), 310-321.

Anderson, J. E. (2011), 'The gravity model', Annual Review of Economics 3(1), 133-160.

Anderson, J. E. and Van Wincoop, E. (2003), 'Gravity with gravitas: a solution to the border puzzle', American Economic Review 93(1), 170 - 192.

Andersson, A. (2018), 'The trade effect of private standards', European Review of Agricultural Economics 46(2), 267-290.

Angeles Diaz-Mayans, M. and Sanchez, R. (2004), 'Temporary employment and technical efficiency in spain', International Journal of Manpower 25(2), 181-194.

Asprilla, A., Berman, N., Cadot, O. and Jaud, M. (2019), 'Trade policy and market power: Firm-level evidence', International Economic Review 60(4), 1647-1673.

Autor, D. H., Kerr, W. R. and Kugler, A. D. (2007), 'Does employment protection reduce productivity? evidence from us states', The Economic Journal 117(521), F189-F217. 
Belot, M., Boone, J. and Van Ours, J. (2007), 'Welfare-improving employment protection', Economica 74(295), 381-396.

Bentolila, S. and Bertola, G. (1990), 'Firing costs and labour demand: how bad is eurosclerosis?', The Review of Economic Studies 57(3), 381-402.

Beverelli, C., Boffa, M. and Keck, A. (2019), 'Trade policy substitution: theory and evidence', Review of world economics 155(4), 755-783.

Black, S. E. and Lynch, L. M. (2001), 'How to compete: the impact of workplace practices and information technology on productivity', Review of Economics and statistics 83(3), 434-445.

Blanchard, O. and Wolfers, J. (2000), 'The role of shocks and institutions in the rise of european unemployment: The aggregate evidence', The Economic Journal 110(462), C1-C33.

Bloom, N. and Van Reenen, J. (2007), 'Measuring and explaining management practices across firms and countries', The quarterly journal of Economics 122(4), 1351-1408.

Boeri, T. and Garibaldi, P. (2007), 'Two tier reforms of employment protection: A honeymoon effect?', The Economic Journal 117(521), F357-F385.

Brorsen, B. W. and Kim, T. (2013), 'Data aggregation in stochastic frontier models: the closed skew normal distribution', Journal of Productivity Analysis 39(1), 27-34.

Brown, A. J. and Koettl, J. (2015), 'Active labor market programsemployment gain or fiscal drain?', IZA Journal of Labor Economics 4(1), 12.

Brunello, G., Garibaldi, P., Wasmer, E. and Bassanini, A. (2007), Education and training in Europe, Oxford University Press.

Calmfors, L. (1993), 'Centralisation of wage bargaining and macroeconomic performance'.

Calmfors, L. and Driffill, J. (1988), 'Bargaining structure, corporatism and macroeconomic performance', Economic policy 3(6), 13-61.

Chaney, T. (2008), 'Distorted gravity: the intensive and extensive margins of international trade', The American Economic Review 98(4), 1707-1721.

Chen, N. and Novy, D. (2018), Currency unions, trade, and heterogeneity, CEPR Discussion Paper No. DP12954.

Christensen, L. R. (1971), 'Conjugate duality and the transcendental logarithmic prodcution function', Econometrica 39, 255-256.

Coelli, T. J., Rao, D. P., O'Donnell, C. J. and Battese, G. E. (1998), 'An introduction to productivity and efficiency analysis', Springer Science: New York

Connolly, R. A., Hirsch, B. T. and Hirschey, M. (1986), ‘Union rent seeking, 
intangible capital, and market value of the firm', The Review of Economics and Statistics pp. 567-577.

Correia, S. (2016), 'REGHDFE: Stata module to perform linear or instrumental-variable regression absorbing any number of highdimensional fixed effects', Statistical Software Components, Boston College Department of Economics.

Crivelli, P. and Gröschl, J. (2016), 'The impact of sanitary and phytosanitary measures on market entry and trade flows', The World Economy 39(3), 444473.

Curzi, D., Luarasi, M., Raimondi, V. and Olper, A. (2018), 'The (lack of) international harmonization of EU standards: import and export effects in developed versus developing countries', Applied Economics Letters pp. 1-5.

Curzi, D., Raimondi, V. and Olper, A. (2015), 'Quality upgrading, competition and trade policy: evidence from the agri-food sector', European Review of Agricultural Economics 42(2), 239-267.

Curzi, D., Schuster, M., Maertens, M. and Olper, A. (2020), 'Standards, trade margins and product quality: firm-level evidence from Peru', Food Policy .

De Loecker, J. (2011), 'Product differentiation, multiproduct firms, and estimating the impact of trade liberalization on productivity', Econometrica 79(5), 1407-1451.

De Loecker, J. and Konings, J. (2006), 'Job reallocation and productivity growth in a post-socialist economy: Evidence from slovenian manufacturing', European Journal of Political Economy 22(2), 388-408.

De Sousa, J. (2012), 'The currency union effect on trade is decreasing over time', Economics Letters 117(3), 917-920.

Di Pietro, G. (2002), 'Technological change, labor markets, and 'low-skill, low-technology traps", Technological forecasting and social change 69(9), 885895.

Dietz, M., Stops, M., Walwei, U. et al. (2010), 'Safeguarding jobs through labor hoarding in germany', Applied Economics Quarterly 61, 125-66.

Dikshit, A. and Birthal, P. S. (2010), 'India's livestock feed demand: estimates and projections', Agricultural Economics Research Review 23(1), 15-28.

Disdier, A.-C., Fontagné, L. and Mimouni, M. (2008), 'The impact of regulations on agricultural trade: evidence from the sps and tbt agreements', American Journal of Agricultural Economics 90(2), 336-350.

Dolado, J. J. and Stucchi, R. (2008), 'Do temporary contracts affect tfp? evidence from spanish manufacturing firms'. 
Doucouliagos, H. and Laroche, P. (2006), Human resource practices, unionization and the organizational efficiency of french industry, in 'Advances in Industrial \& Labor Relations', Emerald Group Publishing Limited, pp. 67102.

Eaton, J. and Kortum, S. (2002), 'Technology, geography, and trade', Econometrica 70(5), 1741-1779.

Egger, P. H. and Nigai, S. (2015), 'Structural gravity with dummies only: Constrained anova-type estimation of gravity models', Journal of International Economics 97(1), 86-99.

Ehrich, M., Brümmer, B. and Martínez-Zarzoso, I. (2017), Exporter size matters - heterogeneous effects of food standards on agricultural trade. Unpublished thesis chapter. Available at https://ediss.uni-goettingen. de/handle/11858/00-1735-0000-0023-3DFB-3.

Ehrich, M. and Mangelsdorf, A. (2018), 'The role of private standards for manufactured food exports from developing countries', World Development 101, 16-27.

Feenstra, R. C. (2003), 'A homothetic utility function for monopolistic competition models, without constant price elasticity', Economics Letters 78(1), 7986.

Feenstra, R. C. (2004), Advanced International Trade: Theory and Evidence, Princeton University Press.

Fernandes, A. M., Ferro, E. and Wilson, J. S. (2019), 'Product standards and firms' export decisions', The World Bank Economic Review 33(2), 353-374.

Ferro, E., Otsuki, T. and Wilson, J. S. (2015), 'The effect of product standards on agricultural exports', Food Policy 50, 68-79.

Fiankor, D.-D. D., Flachsbarth, I., Masood, A. and Brümmer, B. (2020), 'Does globalgap certification promote agrifood exports?', European Review of Agricultural Economics 47(1), 247-272.

Fiankor, D.-D. D., Martínez-Zarzoso, I. and Brümmer, B. (2019), 'Exports and governance: the role of private voluntary agrifood standards', Agricultural Economics .

Fontagné, L., Disdier, A.-C. and Beestermöller, M. (2016), Impact of European food safety border inspections on agri-food exports: evidence from Chinese firms, Technical report, CEPII research center.

Fontagné, L., Orefice, G., Piermartini, R. and Rocha, N. (2015), 'Product standards and margins of trade: firm-level evidence', Journal of International Economics 97(1), 29-44. 
Freeman, R. B. and Medoff, J. L. (1984), ‘What do unions do? new york: Basic books'.

Gaulier, G. and Zignago, S. (2010), 'Baci: international trade database at the product-level (the 1994-2007 version)'.

Ghodsi, M., Grübler, J., Reiter, O., Stehrer, R. et al. (2017), The evolution of non-tariff measures and their diverse effects on trade, Vienna Institute for International Economic Studies.

Grant, J. and Arita, S. (2017), Sanitary and phyto-sanitary measures: Assessment, measurement, and impact, Technical report.

Grant, J. H., Peterson, E. and Ramniceanu, R. (2015), 'Assessing the impact of sps regulations on us fresh fruit and vegetable exports', Journal of Agricultural and Resource Economics pp. 144-163.

Helpman, E., Melitz, M. and Rubinstein, Y. (2008), 'Estimating trade flows: trading partners and trading volumes', Quarterly Journal of Economics 123(2), 441-487.

Hirsch, B. T. (2003), What do unions do for economic performance?, in 'What Do Unions Do?', Routledge, pp. 201-245.

Hirsch, B. T. and Link, A. N. (1987), 'Labor union effects on innovative activity', Journal of Labor Research 8(4), 323-332.

Hirschman, A. O. (1970), Exit, voice, and loyalty: Responses to decline in firms, organizations, and states, Vol. 25, Harvard university press.

Holden, S. and Raaum, O. (1991), 'Wage moderation and union structure', Oxford Economic Papers 43(3), 409-423.

Hummels, D. and Klenow, P. J. (2005), 'The variety and quality of a nation's exports', American Economic Review 95(3), 704-723.

Ichino, A. and Riphahn, R. T. (2005), 'The effect of employment protection on worker effort: Absenteeism during and after probation', Journal of the European Economic Association 3(1), 120-143.

Jordan, E. R., Chapman, T. E., Holtan, D. W. and Swanson, L. V. (1983), 'Relationship of dietary crude protein to composition of uterine secretions and blood in high-producing postpartum dairy cows', Journal of Dairy Science 66(9), 1854-1862.

Karakaplan, M. (2016), 'Sfkk: Stata module to estimate endogenous stochastic frontier models in the style of karakaplan and kutlu'.

Katayama, H., Lu, S. and Tybout, J. R. (2009), 'Firm-level productivity studies: illusions and a solution', International Journal of Industrial Organization 27(3), 403-413. 
Kinzius, L., Sandkamp, A. and Yalcin, E. (2018), 'Trade protection and the role of non-tariff barriers', Review of World Economics pp. 1-41.

Klette, T. J. and Griliches, Z. (1996), 'The inconsistency of common scale estimators when output prices are unobserved and endogenous', Journal of Applied Econometrics 11(4), 343-361.

Koeniger, W. (2005), 'Dismissal costs and innovation', Economics Letters 88(1), 79-84.

Kosfeld, R. and Dreger, C. (2006), 'Thresholds for employment and unemployment: A spatial analysis of german regional labour markets, 19922000', Papers in Regional Science 85(4), 523-542.

Laven, R. and Drew, S. (1999), 'Dietary protein and the reproductive performance of cows', Veterinary Record 145(24), 687-695.

Layard, R., Layard, P. R. G., Nickell, S. J. and Jackman, R. (2005), Unemployment: macroeconomic performance and the labour market, Oxford University Press on Demand.

Lee, L.-f. and Yu, J. (2010), 'Estimation of spatial autoregressive panel data models with fixed effects', Journal of Econometrics 154(2), 165-185.

Link, A. N. and Siegel, D. S. (2002), 'Unions and technology adoption: A qualitative analysis of the use of real-time control systems in us coal firms', Journal of Labor Research 23(4), 615-630.

Lommerud, K. E., Meland, F. and Straume, O. R. (2006), 'Globalisation and union opposition to technological change', Journal of International Economics 68(1), 1-23.

Marschak, J. and Andrews, W. H. (1944), 'Random simultaneous equations and the theory of production', Econometrica, Journal of the Econometric Society pp. 143-205.

Meeusen, W. and van Den Broeck, J. (1977), 'Efficiency estimation from cobbdouglas production functions with composed error', International economic review pp. 435-444.

Melitz, M. J. (2003), 'The impact of trade on intra-industry reallocations and aggregate industry productivity', Econometrica 71(6), 1695-1725.

Menezes-Filho, N. and Van Reenen, J. (2003), 'Unions and innovation: a survey of the theory and empirical evidence'.

Meng, D., Maeda, K. and Wang, X. (2018), 'China's agricultural trade cost elasticity: Estimates from using translog gravity model', Journal of the Faculty of Agriculture, Kyushu University 63(1), 177-184.

Mundlak, Y. (1961), 'Empirical production function free of management bias', Journal of Farm Economics 43(1), 44-56. 
Nickell, S. (1997), ‘Unemployment and labor market rigidities: Europe versus north america', Journal of Economic perspectives 11(3), 55-74.

Nickell, S. and Layard, R. (1999), 'Labor market institutions and economic performance', Handbook of labor economics 3, 3029-3084.

Novy, D. (2013), 'International trade without ces: Estimating translog gravity', Journal of International Economics 89(2), 271-282.

Nunti, C., Boonyakunakorn, P. and Sriboonchitta, S. (2019), Technical efficiency of rice production in thailand: copula-based stochastic frontier model, in 'Journal of Physics: Conference Series', Vol. 1324, IOP Publishing, p. 012107.

Olley, S. and Pakes, A. (1996), 'The dynamics of productivity in the telecommunications equipment industry', Econometrica 64(6), 1263-1297.

Olper, A. (2016), 'The political economy of trade-related regulatory policy: environment and global value chain', Bio-based and Applied Economics 5(3), 287-324.

Orefice, G. (2017), 'Non-tariff measures, specific trade concerns and tariff reduction', The World Economy 40(9), 1807-1835.

Owen, D. B. (1956), 'Tables for computing bivariate normal probabilities', The Annals of Mathematical Statistics 27(4), 1075-1090.

Pal, M. and Sengupta, A. (1999), 'A model of fpf with correlated error componenets: an application to indian agriculture', Sankhyā: The Indian Journal of Statistics, Series B pp. 337-350.

Park, S. and Gupta, S. (2012), 'Handling endogenous regressors by joint estimation using copulas', Marketing Science 31(4), 567-586.

Pratap, B. and Jha, A. (2005), 'Economic losses due to various constraints in dairy production in india', Indian Journal of Animal Sciences 75(12), 14701475.

Rajendran, K. and Mohanty, S. (2005), 'Efficiency of milk production in india: a stochastic frontier production function approach', Indian Journal of Economics and Business 4(2), 275.

Saha, A. and Jain, D. (2004), 'Technical efficiency of dairy farms in developing countries: A case study of haryana state, india', Indian Journal of Agricultural Economics 59(3), 588.

Samaniego, R. M. (2006), 'Employment protection and high-tech aversion', Review of Economic Dynamics 9(2), 224-241.

Santeramo, F. G. and Lamonaca, E. (2019), 'The effects of non-tariff measures on agri-food trade: A review and meta-analysis of empirical evidence', Journal of Agricultural Economics 70(3), 595-617. 
Santos Silva, J. M. C. and Tenreyro, S. (2006), 'The log of gravity', The Review of Economics and Statistics 88(4), 641-658.

Shapiro, C. and Stiglitz, J. E. (1984), 'Equilibrium unemployment as a worker discipline device', The American Economic Review 74(3), 433-444.

Sharma, V. P., Delgado, C. L., Staal, S. and Singh, R. V. (2003), 'Policy, technical, and environmental determinants and implications of the scaling up of milk production in india'.

Smith, M. D. (2008), 'Stochastic frontier models with dependent error components', The Econometrics Journal 11(1), 172-192.

Swinnen, J. (2016), 'Economics and politics of food standards, trade, and development', Agricultural Economics 47(S1), 7-19.

Tran, K. C. and Tsionas, E. G. (2015), 'Endogeneity in stochastic frontier models: Copula approach without external instruments', Economics Letters 133, 85-88.

Van Beveren, I. (2012), 'Total factor productivity estimation: A practical review', Journal of economic surveys 26(1), 98-128.

Weinstein, M. A. (1964), 'Query 2: The sum of values from a normal and a truncated normal distribution', Technometrics 6(1), 104-105.

WHO (1950), 'Joint FAO/WHO Expert Committee on Nutrition: report on the first session, Geneva, 24-28 October 1949', WHO Technical Report Series (16), 1-24.

Wiboonpongse, A., Liu, J., Sriboonchitta, S. and Denoeux, T. (2015), 'Modeling dependence between error components of the stochastic frontier model using copula: application to intercrop coffee production in northern thailand', International Journal of Approximate Reasoning 65, 34-44.

WTO (2012), World Trade Report 2012: Trade and Public Policies: a Closer Look at Non-tariff Measures in the 21st Century, World Trade Organization.

Xiong, B. and Beghin, J. (2014), 'Disentangling demand-enhancing and tradecost effects of maximum residue regulations', Economic Inquiry 52(3), 11901203. 